\title{
Ownership Structure, Income Distribution, and Competitive Equilibrium: A Theory of Business Cycles, Human Capital, and Asset Returns*
}

\author{
Qiang Dai
}

August 16, 2000

${ }^{*}$ The author is at Stern School of Business, New York University. Email: qdai@stern.nyu.edu. I wish to thank Ken Singleton and David Backus for helpful discussions. All errors are mine. 


\begin{abstract}
In this paper, I present a theory of dynamic economic growth, business cycles, and asset pricing that integrates (1) Marx's idea (and emphasized by Klein) of a two-class heterogeneity of the ownership structure of physical capital and human capital in a capitalist economy, (2) Keynes' idea of sticky wage rates, and (3) the existence of a competitive equilibrium with intertemporal consumption and portfolio decisions by risk-averse capitalists facing a contractual labor cost.

The aggregate labor income as a function of recent history of aggregate outputs is determined by the prevailing mode of income distribution. I focus on a modern capitalist economy in which the income distribution is not dictated by the capitalists (as in the formative years of capitalism which was the subject of inquiry by Adam Smith, David Ricardo, and Karl Max), but rather is determined by the economic and political consensus reached between the capitalists and workers through a legal and political framework featuring strong labor unions, anti-trust laws, and progressive tax codes.

Three main implications for the macro-economy are presented. First, my theory endogenizes completely the three-equation Klein model of consumption function, savings function, and the wage demand function. Second, I show that cyclic behavior is driven entirely by the assumed form of income distribution. Production and labor income shocks do not drive, but help sustain the cyclic behavior by preventing the economy from converging to the steady state mean. Third, I show that the Marxian doctrine that the "rate of surplus value" remains constant and the "organic composition of capital" keeps rising is inconsistent with the predictions of my model, and the difference is traced to the different assumptions on income distribution, and leads to different conclusions on the stability of capitalist economies.

By assuming that capital markets clear in equilibrium, I determine the risk premium for both production and labor income risks, and consequently asset returns and the value of human capital - all endogenously. A special case of the model is observationally equivalent to the stochastic habit formation model of Dai (2000a), and thus inherits its ability to simultaneously explain the equity premium puzzle, riskless rate puzzle, and the expectations puzzle. In general, the labor market need not clear, due to the only friction in the model: the longevity of the labor contract.
\end{abstract}




\section{Contents}

1 Introduction $\quad 3$

2 A Discrete-Time General Equilibrium Model With Riskless Production $\begin{array}{ll}\text { and Deterministic Labor Income } & 7\end{array}$

2.1 Model Assumptions . . . . . . . . . . . . . . . . . . . 7

2.2 Solving the Capitalist's Optimal Consumption Problem . . . . . . . . . . 11

2.3 Implications for the Macro-economy . . . . . . . . . . . . . . . . 14

2.3.1 Endogenizing Klein's Model of the Consumption Function . . . . . . 14

2.3.2 Cyclic Behavior in the Real Deterministic Economy . . . . . . . . . 14

2.3.3 Relation to Marxian Economics . . . . . . . . . . . . . . 15

3 A Continuous-Time General Equilibrium Model with Production Shocks $\begin{array}{ll}\text { and Labor Income Risk } & 17\end{array}$

3.1 Model Assumptions . . . . . . . . . . . . . . . . . . . . 18

3.2 Relation to Habit Formation Models . . . . . . . . . . . . . . . 19

3.3 Long-term Growth and Short-term Fluctuations . . . . . . . . . . . 20

3.4 Admissible Labor Contracts . . . . . . . . . . . . . . . . . . . . 21

3.5 Optimal Consumption and Portfolio Policies . . . . . . . . . . . . . 22

3.6 Pricing Kernel (with Production and Labor Income Risks) . . . . . . . . . 24

3.7 Determinants of Human Capital . . . . . . . . . . . . . . . . . 24

3.7.1 A Special Case: Risky Production and Deterministic Labor Income . 26

3.7.2 Another Special Case: Stochastic labor Contract . . . . . . . . . . 27

3.8 Labor Contracts with Pro-cyclic Riskless Rate . . . . . . . . . . . . 28

4 A Two-factor Capital Asset Pricing Model with Human Capital 30

4.1 Defining Returns . . . . . . . . . . . . . . . 30

4.2 Pricing Equities . . . . . . . . . . . . . . . . . . . 31

5 Structural Link between the Macroeconomy and the Term Structure of Real Interest Rates

6 Conclusion $\quad 35$

$\begin{array}{ll}\text { A The Main Proposition } & 36\end{array}$

B Proof of Proposition 1: Incomplete Market Case 39

B.1 First Order Conditions . . . . . . . . . . . . . . . . . . 39

B.2 Investment Opportunity Set . . . . . . . . . . . . . 40

B.3 Market Clearing Conditions . . . . . . . . . . . . . . 41

B.4 Transversality Condition . . . . . . . . . . . . . . . 42

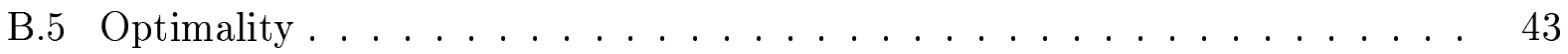

C Proof of Proposition 1: Complete Market Case and the Derivation of the Pricing Kernel 


\section{Introduction}

In the last several decades, dynamic economic models based on rational expectations and intertemporal optimization under uncertainty have enjoyed considerable success in helping economists understand not only the behavior of capital markets, ${ }^{1}$ but also the behavior of the macro-economy, including the dynamics of economic growth and business cycles ${ }^{2}$ and the behavior of aggregate consumption ${ }^{3}$

Yet, there is a sense that something important is still amiss. First, despite their elegance and theoretical plausibility, dynamic asset pricing models have been confronted with serious empirical challenges. For examples, financial economists have so far failed to come up with a simple story that explains the equity premium puzzle of Mehra and Prescott (1985), the riskfree rate puzzle of Weil (1989), and the expectations puzzle of Campbell and Shiller (1991). Similarly, real business cycle models have trouble reconciling the empirical observations that most economic downturns are not preceded by any major production shocks, and that labor income is sticky. ${ }^{4}$ Second, even though most dynamic asset pricing theories and real business cycle models are based on the same economic paradigm of rational expectation and dynamic optimization, their assumptions about agents' endowments, technologies, and preferences are not necessarily consistent with each other. The fact that there does not exist a unified theory that speaks to both the aggregate asset market behavior and the macro-economic behavior suggests that there are fundamental theoretical issues that the received literature has yet to address.

In this paper, I will demonstrate that a key element missing in both existing dynamic asset pricing models and real business cycle models is the old Keynesian idea of sticky wages or labor income, and that by modeling labor income properly, it is possible to unify a realistic theory of financial markets with a realistic theory of economic growth, business cycles, consumption, and employment. At the intersection of the financial and macroeconomic theories lies a realistic theory of labor income and human capital.

Specifically, I present a model that contains the following three key elements.

1. Heterogeneous ownership of physical and human capital. That is, a capitalist owns the physical capital, and a worker owns the human capital.

2. A single source of friction in the form of long-term labor contract, or sticky labor income.

3. The existence of a competitive equilibrium with intertemporal consumption and investment decisions by risk averse capitalists facing a contractual labor income.

Heterogenous ownership structure is one of the cornerstones of Marxian economics. The empirical fact that wages are sticky reflects labor market frictions, and is one of the cornerstones of Keynesian economics. Both elements are embedded in Klein (1950)'s three-equation statistical model of aggregate consumption, savings, and labor income. Unfortunately, Klein's

\footnotetext{
${ }^{1}$ See, e.g., Lucas (1978), Merton (1992), Duffie (1996), Campbell (2000), and Sundaresan (2000).

${ }^{2}$ See, e.g., Kydland and Prescott (1982) and Long and Plosser (1983).

${ }^{3}$ See, e.g., Friedman (1957) and Weil (1993).

${ }^{4}$ See, e.g., critiques by Summers (1986) and Mankiw (1989).
} 
model, as a description of endogenous variables, was exogenously specified, although he tried to motivate the model by appealing to basic economic models. Asset prices in an exchange economy can be modeled without referring to these two elements at all, effectively taking the aggregate consumption as exogenously given. ${ }^{5}$ Real business cycle models, on the other hand, endogenize everything in a Walrasian economy, in which both capital and labor markets clear. While the heterogenous ownership structure is partially embedded in real business cycle models ${ }^{6}$ labor income is completely flexible and efficient, contradicting the the empirical observation that wage income is sticky. Proponents of real business cycle models are sharply opposed to Keynesian economists, who believe that it is the sticky labor income, rather than production shocks, that is responsible for business cycles.

My model, together with a companion paper on labor income determination, completely endogenizes aggregate labor income, consumption, and savings. It is almost parallel to real business cycles models, except for two critical differences. The first difference is that workers (represented by labor unions) in my model are monopoly sellers of their labor service, ${ }^{7}$ while workers in real business cycle models are competitive price takers in the labor market. Another difference is that there are two agents (or two classes of homogeneous agents) in my model: the capitalist and the worker, who have different sources of income, different saving behaviors, and different welfare functions, while there is only one agent, Robinson Crusoe, in real business cycle models. These two differences lead to completely opposite predictions on (a) the cause and behavior of real business cycles; and (b) whether there is scope for sticky wages and involuntary unemployment. Indeed, my model may be viewed as an analytical expression of the Keynesian perspective on business cycle and labor income - in a dynamic setting.

In this paper, I shall abstract away from the mechanism of labor income determination, and focus exclusively on how, taking a labor income process as given, to determine optimal consumption and savings policies and derive general equilibrium pricing implications. This problem can be thought of as the second part of a two-stage Stackelberg wage game between a monopolist union and a competitive firm, in the sense of Leontief (1946). In the companion paper, Dai (2000b), I will show that the Stackelberg game can be expressed as a dynamic extensive form game and the labor contracts assumed here emerge as time-consistent solutions (or sub-game perfect strategies) to the wage game.

In the rest of the introduction, I will give a brief description of the simplest form of the model - the model in a deterministic and discrete-time setting, and comment on the difference between this model and several related models in the macro-economic literature. A full-fledged model with production shocks and labor income risk will be introduced later.

I begin by assuming that there are two homogeneous class of economic agents: the capitalists and the workers. Since each class of economic agents are homogeneous, we can instead think of the economy as consisting of two agents: the capitalist and the worker. A critical modeling assumption is the form of income distribution, which, in its simplest form, is a variation of Klein's wage demand function. Instead of modeling the expected labor

\footnotetext{
${ }^{5}$ See Lucas (1978).

${ }^{6}$ In real business cycle models, there are two sources of income: financial and labor. However, there is only a single representative agent.

${ }^{7}$ The union sets both the total wage bill and the employment level, as in Leontief (1946).
} 
income as a function of current output and lagged output, I assume that the expected labor income is a weighted sum of current and all past consumptions, which, in equilibrium, is equivalent to the assumption that the labor income is a weighted sum of current and all past outputs. The weights decay exponentially, so that the number of free parameters is the same as Klein's wage demand function.

Specifically, I assume that the per capita ${ }^{8}$ labor income is given by

$$
x_{t+1}=b \sum_{j=0}^{\infty}(1-\kappa)^{j} z_{t-j},
$$

where $x_{t}$ is the per capita labor income, $z_{t}$ is the per capita consumption by the capitalists, $b$ and $\kappa$ are constants. Following Klein (1950), I assume that the workers do not save and consume all their labor income in every period. It follows that the aggregate consumption per capita, $c_{t}$, is simply the sum of $x_{t}$ and $z_{t}$. Defining $a=\kappa+b$, one can show easily that equation (1) is equivalent to

$$
x_{t+1}=b \sum_{j=0}^{\infty}(1-a)^{j} c_{t-j} .
$$

Later, we will also show that, in equilibrium, equations (1) and (2) are equivalent to

$$
x_{t+1}=b^{\prime} \sum_{j=0}^{\infty}\left(1-a^{\prime}\right)^{j} y_{t-j},
$$

where $y_{t}$ is the aggregate output per worker employed. The similarities and differences between (3) and Klein's wage demand function, $x_{t+1}=\gamma_{0}+\gamma_{1} y_{t}+\gamma_{2} y_{t-1}+u_{t+1}$, is apparent.

The labor income is sticky in the sense that once the labor contract and initial labor income $x_{0}$ are agreed upon at time 0 , subsequent wage increases will not deviate from the amount stipulated by the wage contract: ${ }^{9}$

$$
x_{t+1}-x_{t}=b z_{t}-\kappa x_{t} \equiv b c_{t}-a x_{t}
$$

which is equivalent to equation (1). Thus equation (1) may be viewed as a (stylized) analytical expression of the Keynesian perspective on wage stickiness. Since the labor income increases only gradually as the economy expands $\left(z_{t}\right.$ increases $)$, labor may be in short supply. Similarly, when the economy contracts ( $z_{t}$ decreases), the labor income can only decrease gradually, thereby inducing an unemployment rate above the natural rate. ${ }^{10}$ We will show that, in our model, the wage stickiness is solely responsible for the cyclic behavior of the real economy.

\footnotetext{
${ }^{8}$ Throughout the paper, per capita means per worker. Thus, the "per capital consumption by the capitalists" means the total consumption by the capitalists divided by the population of the labor force, not by the population of the capitalists.

${ }^{9}$ In Dai (2000b), I show that the labor contract is not only ex ante optimal, but also ex post optimal. In another word, the contract is time-consistent.

${ }^{10}$ Mean reversion of the labor income may be partially driven by a state-dependent labor supply.
} 
A capitalist faces a standard problem of consumption choice and portfolio selection, with the wage rate entering his budget constraint as the cost of labor. To complete the specification of the capitalist's problem, we assume that the capitalist has a time-additive expected power utility function over his life-time consumption, $z_{t}, 0 \leq t \leq \infty$. In equilibrium, the capital markets clear. However, the labor market need not.

This is a very simple model, which also turns out to be very tractable. ${ }^{11}$ Yet, in two important respects, it is very different from the permanent income model of Friedman (1957), the neo-classical growth models of Solow (1956) and Solow (1957), and the consumption based asset pricing model of Lucas (1978) and Breeden (1979): heterogeneity in the ownership structure of physical and human capital and friction in the form of infinite duration for the labor contract. All of these models share a basic structure of a frictionless Robinson Crusoe economy.

Models with habit persistence (but without labor income or labor cost in the budget constraint) also have the appearance of a frictionless Robinson Crusoe economy. However, I will show that my model is mathematically, and therefore observationally, equivalent to a model with habit persistence. The resemblance between the empirical consumption function based on distributed lags of labor income and habit persistence was first noted by Brown (1952). The mathematical equivalence I establish in this paper suggests a stronger conjecture: consumption habit is simply a measure of labor cost or labor income. It follows that consumption smoothing due to habit persistence is really due to the nature of income distribution.

The labor income represents labor's share of national product after the redistribution effects of government taxes and transfers. It can be formally justified in a variety of ways. Klein (1950) himself makes the link of his model to Kalecki's business cycle models and Marxian theory of effective demand. Brown (1952) notes the contractual aspect of labor income from the perspective of distribution theory. Before him, Leontief (1946) gives an excellent exposition on the nature of wage contracts under different labor market mechanisms or relative bargaining power between the capitalist (corporations) and the worker (unions) in labor contract negotiations. A particular version of Leontief's model is a Stackelberg (1934) game in which the worker, who is a monopoly seller of labor, moves first and presents a labor contract stipulating both the total wage bill and the employment level; and the capitalist, who takes the labor contract as given, works out his optimal consumption and investment policies (see Gibbons (1992)).

My model has the flavor of Leontief's Stackelberg game in terms of wage determination. However, the dynamic nature of the problem examined in this paper allows us to take an entirely different approach to justifying the form of the labor contract. Specifically, I will start by assuming that labor income is a generic stochastic process controlled by the capitalist's consumption. I will then impose specific restrictions on the labor contract so that the solution to the resulting model possess some general properties, such as homotheticity, scale-independence, and stationarity (more generally the existence of an economy that grows

${ }^{11}$ To the author's knowledge, this model has not been studied before, even though the continuous-time version of the model turns out to be observationally equivalent to the habit formation models of Sundaresan (1989) and Constantinides (1990) and a special case of Dai (2000a). It is not obvious, a priori, that the discrete-time model admits an analytical solution. 
continually), that are desirable to both the worker and the capitalist. One can think of this procedure as a backward induction process by the worker in determining the wage demand. It turns out that the general properties that I appeal to impose such severe restrictions on specific forms of the labor contracts that, from an empirical standpoint, the procedure almost obviates the need for a separate justification based on wage bargaining. ${ }^{12}$

The rest of the paper is organized as follows. Section 2 presents a deterministic, discretetime economy with two agents, one production technology, and a linear labor contract. Section 3 presents a continuous-time model under uncertainty. The continuous-time formulation is dictated by tractability. I will derive the most general form of labor contract that supports a scale-independent and stationary economy. Taking the labor contract as given, I will solve analytically for the capitalist's optimal consumption and portfolio decisions, and characterize the investment opportunity set and pricing kernel in equilibrium. In Sections 4 and 5, I will explore the implications of the general model for equity and bond pricing, respectively. In particular, I will derive a two-factor consumption based asset pricing model with human capital, and a two-factor consumption based term structure of real interest rates. I will conclude in Section 6.

\section{A Discrete-Time General Equilibrium Model With Riskless Production and Deterministic Labor Income}

Suppose that the capitalist initially owns the physical capital $K_{0}$. In order to finance future consumption, he invests the physical capital in a riskless production technology that pays a real rate of return $R$. The aggregate dividend (aggregate output less saving) derived from the investment policy will pay for, not only the consumption by the capitalist, but also the consumption by the worker. The capitalized value of the capitalist's consumption will be less than $K_{0}$, with the balance being the capitalized value of the worker's consumption, which, by definition, is the human capital. Thus, in our definition, human capital is part of the physical capital.

\subsection{Model Assumptions}

Assumption 1 (Production Technology) In each period, the net national product, or total output after depreciation of physical capital but before labor cost, is given by

$$
Y_{t}=R_{t}\left(K_{t}-Z_{t}-w_{t} L_{t}\right)
$$

where $K_{t}$ is the physical capital at the beginning of time period $t, L_{t}$ is the labor force employed, $w_{t}$ is the per capita wage rate, ${ }^{13}$ and $Z_{t}$ is the capitalist's consumption,

\footnotetext{
${ }^{12}$ Theoretically, it is important to show that the labor contracts are optimal (preferably sub-game perfect) from the worker's perspective. This is precisely the focus of Dai (2000b).

${ }^{13} w_{t}$ is the average labor income per worker employed. This is distinct from the the per capita labor income, $x_{t}$, which is the aggregate labor income, $w_{t} L_{t}$, divided by the total population of the labor force, $H_{t}$. Obviously, $x_{t}=w_{t} l_{t}$, where $l_{t}=L_{t} / H_{t}$ is the employment rate.
} 
The production technology (1) can be justified by a constant-return-to-scale production function. Specifically, let the gross national product (total output before depreciation and labor cost) be given by

$$
\hat{Y}_{t}=A_{t} F\left(\hat{K}_{t} / L_{t}\right) L_{t}
$$

where $\hat{K}_{t}$ is the net physical input, $A_{t}>0$ represents the level of technology, and $0<\alpha<1$. Let $\delta_{t}$ be the depreciation rate of the physical capital. Following Leontief (1946), we assume that the worker sets both the total wage bill $X_{t}=w_{t} L_{t}$, and the employment level $L_{t}$, so that the capitalist chooses the amount of capital to maximize his profit. That is, the capitalist solves

$$
\max _{\hat{K}_{t}} A_{t} F\left(\hat{K}_{t} / L_{t}\right) L_{t}-\delta_{t} \hat{K}_{t}-X_{t}
$$

Assuming that $A_{t}$ does not depend on $L_{t}$ and $\hat{K}_{t},{ }^{14}$ the first order condition is

$$
F^{\prime}\left(\hat{K}_{t} / L_{t}\right)=\frac{\delta_{t}}{A_{t}}
$$

Let $\Phi(\cdot)$ is the inverse function of $F^{\prime}(\cdot)$, we have

$$
\hat{K}_{t}^{*}=\Phi\left(\delta_{t} / A_{t}\right) L_{t}
$$

Since the total wage bill is $X_{t}$, and the capitalist himself consumes $Z_{t}$, the net supply of physical capital available for production input is given by $K_{t}-Z_{t}-X_{t}$. We assume that the worker chooses the employment level so the the capital market clears:

$$
\hat{K}^{*}=K_{t}-Z_{t}-X_{t}
$$

which implies that

$$
L_{t}=\frac{K_{t}-Z_{t}-X_{t}}{\Phi\left(\delta_{t} / A_{t}\right)}
$$

Thus, in equilibrium, the net national product is given by

$$
Y_{t}=A_{t} F\left(\hat{K}_{t} / L_{t}\right) L_{t}-\delta_{t} \hat{K}_{t}=R_{t}\left(K_{t}-Z_{t}-X_{t}\right)
$$

where

$$
R_{t}=A_{t}\left[\frac{F\left(\Phi\left(\delta_{t} / A_{t}\right)\right)}{\Phi\left(\delta_{t} / A_{t}\right)}-\delta_{t} / A_{t}\right]
$$

To get the capitalist's budget constraint, we make the following assumption.

\footnotetext{
${ }^{14}$ Since I are considering an aggregate model, allowing $A_{t}$ to depend on $L_{t}$ and $\hat{K}_{t}$ would break the constant return to scale assumption. This is different from Romer (1994).
} 
Assumption 2 (Saving and Capital Accumulation) The capitalist invests everything that he does not consume in the physical production. That is, the saving is given by

$$
I_{t}=Y_{t}-w_{t} L_{t}-Z_{t}
$$

and the physical capital accumulates according to

$$
K_{t+1}=K_{t}+I_{t} .
$$

Combining Assumptions 1 and 2, I obtain

$$
K_{t+1}=\left(1+R_{t}\right)\left(K_{t}-Z_{t}-w_{t} L_{t}\right),
$$

Let $H_{t}$ be the population of the work force. To define the problem in the per capita basis, I make the following assumption (see Solow (1956)) on population growth:

Assumption 3 (Population Growth) The population growth is solely responsible for the secular trend in the aggregate output and consumption. Furthermore, the growth rate per period is at most a function of $k_{t}, x_{t}$, and possibly time $t$, so that the total population at time $t$ is given by

$$
H_{t}=H_{0} \prod_{s=0}^{t-1}\left(1+G_{t}\right)
$$

In terms of the per capita variables, defined by

$$
\begin{aligned}
y_{t} & =Y_{t} / H_{t}, k_{t}=K_{t} / H_{t}, z_{t}=Z_{t} / H_{t}, \\
l_{t} & =L_{t} / H_{t}, x_{t}=w_{t} L_{t} / H_{t}=w_{t} l_{t}, r_{t}=\frac{1+R_{t}}{1+G_{t}}-1,
\end{aligned}
$$

the budget constraint can be written as

$$
k_{t+1}=\left(1+r_{t}\right)\left(k_{t}-z_{t}-x_{t}\right) .
$$

Assumption 4 (Welfare Function) The capitalist's welfare is determined by a time-additive power utility function:

$$
U_{0}=\sum_{t=0}^{\infty} \beta_{t} \frac{Z_{t}^{\gamma}}{\gamma}
$$

where $\gamma<0$, and $\beta_{0}=1$.

From Assumption 3, I have

$$
U_{0}=H_{0}^{\gamma} \sum_{t=0}^{\infty} \beta^{t} \frac{z_{t}^{\gamma}}{\gamma}
$$


where $\beta=\frac{\beta_{t+1}}{\beta_{t}}\left(1+G_{t}\right)^{\gamma}$ is the subject discount factor, adjusted by the growth rate. I will assume that $\beta$ is a constant, and $0<\beta<1$. Since $H_{0}^{\gamma}$ is a constant, I will ignore it from now on.

Thus, the capitalist's problem, in scaled form, is

$$
\max _{z_{t}: 0 \leq t \leq \infty} \sum_{t=0}^{\infty} \beta^{t} \frac{z_{t}^{\gamma}}{\gamma}
$$

subject to the budget constraint:

$$
k_{t+1}=(1+r)\left(k_{t}-z_{t}-x_{t}\right)
$$

To close the model, I need to say something about per capita wage bill, $x_{t}=\frac{X_{t}}{H_{t}}$.

Assumption 5 (Labor Contract) The wage is determined by a wage contract which calls for an initial wage bill of $X_{0}$, and future wage increases given by

$$
X_{t+1}-X_{t}=b Z_{t}-\kappa_{t} X_{t}
$$

That is, whether the wage increases or decreases depends on the current wage level is above or below a multiple of the current consumption level, $\frac{b}{\kappa_{t}} Z_{t}$, by the capitalist. When the economy is booming, the capitalist's consumption increases, the growth rate of labor income increases. When the economy is declining, the capitalist's consumption decreases, the growth rate of wage income declines. Assuming that $0<1-\kappa_{t}<1$, and denoting the lag operator by $\mathcal{L}$, I can also write

$$
X_{t+1}=b\left(1-\left(1-\kappa_{t}\right) \mathcal{L}\right)^{-1} Z_{t}=b \sum_{j=0}^{\infty}\left(1-\kappa_{t}\right)^{j} Z_{t-j}
$$

that is, the wage level in the next period is the weighted sum of current and past consumptions by the capitalist, and is independent of next period's consumption by the capitalist. Thus, any one-period gain or loss from the production will impact the capitalist's consumption first, and affects the wage rate on a delayed basis. This is consistent with the notion in distribution theory that the contractual wage takes the top portion of the aggregate output, and the capitalist retains the residual portion, which is then split into consumption and saving.

Assumption 3 implies that the per capita wage bill, $x_{t}$, is given by

$$
x_{t+1}-x_{t}=b z_{t}-\kappa x_{t}
$$

where $\kappa=\kappa_{t}+G_{t}$ is assumed to be a constant.

Equations (22), (23), and (26) define the capitalist's optimal consumption problem under a labor contract.

This model departs from neo-classical growth models (e.g., Solow (1956) and Solow (1957)) by assuming that the per capital wage or labor income is a time-varying, endogenous 
variable. ${ }^{15}$ This model is also different from the real business cycle models (e.g., Kydland and Prescott (1982) and Long and Plosser (1983)) in that the labor contract is not the outcome of a Walrasian equilibrium. Rather, I prefer to think of it as the outcome of a bargaining process between the worker and the capitalist, in the sense of Leontief (1946). If workers form a monopoly (a strong union), while firms are competitive buyers in the labor market, the workers can dictate a labor contract, and the firms will take it as given in determining optimal saving and production policies. In reality, the labor contract may also reflect the relative bargaining power, both economic and political, of the workers and the firms. In this paper, I abstract away from the actual mechanism of the bargaining process. All I assume is that the labor contract specified in Assumption 5 is the outcome of such a bargaining process. It is useful to note an interior solution to the bargaining process is possible, because if the worker is too aggressive in his wage demand, he may very well decimate the economy in the sense that the capitalist may find no incentive to engage in production at all.

\subsection{Solving the Capitalist's Optimal Consumption Problem}

To solve the capitalist's problem, I apply the dynamic programming method. ${ }^{16}$

Define the value function as,

$$
J(k, x)=\max _{z_{s}: t \leq s \leq \infty} \sum_{s=t}^{\infty} \beta^{s-t} \frac{z_{s}^{\gamma}}{\gamma},
$$

subject to the constraint (23) and labor contract (26), and initial condition $k_{t}=k$ and $x_{t}=x$,

Then the problem becomes:

$$
J(k, x)=\max _{z}\left[\frac{z^{\gamma}}{\gamma}+\beta J\left(k_{1}, x_{1}\right)\right]
$$

where

$$
\begin{aligned}
& k_{1}=(1+r)(k-z-x), \\
& x_{1}=b z+(1-\kappa) x .
\end{aligned}
$$

The first order condition gives

$$
\begin{aligned}
z^{* \gamma-1} & =\beta(1+r) J_{k}\left(k_{1}, x_{1}\right)-\beta b J_{x}\left(k_{1}, x_{1}\right) \\
& =\beta(1+r) J_{k}\left((1+r)\left(k-z^{*}-x\right), b z^{*}+(1-\kappa) x\right) \\
& -\beta b J_{x}\left((1+r)\left(k-z^{*}-x\right), b z^{*}+(1-\kappa) x\right) .
\end{aligned}
$$

\footnotetext{
${ }^{15}$ Strictly speaking, the labor income is partially exogenous - in the sense that the functional form of the wage increase is exogenously specified, and partial endogenous - in the sense that the functional form of the wage increase depends on the capitalist' consumption, which is an endogenous variable.

${ }^{16}$ For a good reference on dynamic programming in discrete-time, see Stokey et al. (1989).
} 
Envelope theorem implies:

$$
\begin{aligned}
J_{k}(k, x)= & \beta(1+r) J_{k}\left((1+r)\left(k-z^{*}-x\right), b z^{*}+(1-\kappa) x\right), \\
J_{x}(k, x)= & -\beta(1+r) J_{k}\left((1+r)\left(k-z^{*}-x\right), b z^{*}+(1-\kappa) x\right) \\
& +\beta(1-\kappa) J_{x}\left((1+r)\left(k-z^{*}-x\right), b z^{*}+(1-\kappa) x\right) .
\end{aligned}
$$

Combining these two equations, I have

$$
r=(1-\kappa) \frac{J_{x}\left(k_{1}, x_{1}\right)}{J_{k}\left(k_{1}, x_{1}\right)} \frac{J_{k}(k, x)}{J_{k}(k, x)+J_{x}(k, x)} .
$$

Furthermore, substituting the optimal solution back to equation (28) yields:

$$
J(k, x)=\frac{z^{* \gamma}}{\gamma}+\beta J\left((1+r)\left(k-z^{*}-x\right), b z^{*}+(1-\kappa) x\right) .
$$

In order to explicitly solve for the optimal consumption policy, I make the following assumption:

\section{Assumption 6 (Value Function)}

$$
J(k, x)=\phi \frac{(k-f(x))^{\gamma}}{\gamma},
$$

for some smooth, real function $f(\cdot)$.

Substituting equation (36) into equation (31), I have

$$
z^{*}=h(k, x)\left(k_{1}^{*}-f\left(x_{1}^{*}\right)\right)
$$

where

$$
\frac{h(k, x)^{\gamma-1}}{\phi}=\beta\left(1+r+b f^{\prime}\left(x_{1}^{*}\right)\right)
$$

and

$$
\begin{aligned}
k_{1}^{*} & =(1+r)\left(k-z^{*}-x\right), \\
x_{1}^{*} & =(1-\kappa) x+b z^{*}
\end{aligned}
$$

Equations (37) through (40) can be solved jointly to obtain the optimal consumption policy $z^{*}$, as well as next period's physical capital stock $k_{1}^{*}$ and wage level $x_{1}^{*}$, explicitly as a function of the state variables $k$ and $x$.

Substituting equation (37) into equations (34), I obtain the equilibrium riskless rate

$$
r=\frac{f^{\prime}\left(x_{1}^{*}\right)(1-\kappa)}{f^{\prime}(x)-1}-1
$$


Substituting equations (37) and (36) into equations (32) and (35), which are then combined, I obtain

$$
r=\left(1+\frac{h(k, x)^{\gamma}}{\beta \phi}\right) \frac{k_{1}^{*}-f\left(x_{1}^{*}\right)}{k-f(x)}-1 .
$$

For any pair of $k$ and $x$, equations (41) and (42) determines $r=r(k, x)$ and $f=f(x)$. Thus, the unknown functions $r(k, x)$ and $f(x)$ are uniquely determined. It is easy to show that that a feasible solution, and therefore the only solution, is

$$
f(x)=\eta x, r(k, x)=\bar{r},
$$

where $\eta$ and $\bar{r}$ are constants, provided that

$$
\begin{aligned}
\bar{r} & =\frac{1-\kappa \eta}{\eta-1} \\
\hat{h} & =[\phi \beta(1+\bar{r}+b \eta)]^{\gamma-1}, \\
\phi & =\frac{\bar{h}^{\gamma}}{\hat{h}^{\gamma}-\beta \bar{h}^{\gamma}},
\end{aligned}
$$

where

$$
g \equiv \frac{\bar{h}}{\hat{h}}=\frac{k_{1}^{*}-\eta x_{1}^{*}}{k-\eta x}=\frac{1+\bar{r}}{1+\hat{h}(1+\bar{r}+b \eta)}=\frac{(\bar{r}+\kappa)(1+\bar{r})}{\bar{r}+\kappa+(\bar{r}+\kappa+b)(1+\bar{r}) \hat{h}} .
$$

Thus, $k_{1}^{*}-\eta x_{1}^{*}$ is proportional to $k-\eta x$, and the optimal consumption policy can now be written as

$$
z^{*}=\bar{h}(k-\eta x)
$$

If we observe $g$, the permanent growth rate of the per capita economy, then equation (47) and equations (44) through (46) uniquely determine the four unknown parameters: $\bar{r}, \hat{h}, \eta$, and $\phi$. If the permanent growth rate of the economy is accounted for entirely by population growth, then $g=1$.

In order for the solution to be well-defined and economically sensible, I require that

$$
\phi>0, \eta>0
$$

which implies that

$$
g=\frac{\bar{h}}{\hat{h}}<\beta^{\frac{1}{\gamma}}, \bar{r}+\kappa>0 .
$$

The first inequality ensures that $k-f(x)$ does not grow too fast. The second inequality ensures that the labor cost does not grow too fast. Note that with $\beta<1$, an economy with constant per capital income and consumption (i.e., $g=1$ ) would be ruled out if $\gamma \geq 0$. This is why we assume $\gamma<0 .{ }^{17}$

\footnotetext{
${ }^{17}$ This is consistent with Dai (2000a), who shows that when $\gamma>0$, the stochastic habit formation model can still explain the equity premium puzzle and expectations puzzle. However, the resulting economy would be dynamically unstable.
} 


\subsection{Implications for the Macro-economy}

\subsubsection{Endogenizing Klein's Model of the Consumption Function}

The total profit for each period is given by

$$
\pi_{t}=y_{t}-x_{t}=r\left(k_{t}-z_{t}-x_{t}\right)-x_{t} .
$$

It follows that

$$
c_{t}=\alpha_{1} x_{t}+\alpha_{2} \pi_{t}
$$

where

$$
\alpha_{1}=\frac{1+\bar{r}(1-\bar{h} \eta)}{\bar{r}(1-\bar{h})}, \alpha_{2}=\frac{\bar{h}}{\bar{r}(1-\bar{h})} .
$$

Since there is no income risk, there is no precautionary saving (the intercept is zero). Thus, I recover Klein's consumption function.

Next, the incremental saving or investment by the capitalist is given by

$$
\begin{aligned}
i_{t} & =y_{t}-c_{t}=\pi_{t}-z_{t} \\
& =\left(1-\frac{\bar{h} \eta}{1+\bar{r}(1-\bar{h} \eta)}\right) \pi_{t}-\left(\frac{\bar{h}(1+\bar{r}(1-\eta))}{1+\bar{r}(1-\bar{h} \eta)}\right) k_{t} \\
& =\beta_{1} \pi_{t}+\beta_{2} \pi_{t-1}+\beta_{3} k_{t-1},
\end{aligned}
$$

where

$$
\beta_{1}=1, \quad \beta_{2}=-\frac{\bar{h} g(1+\bar{r}(1-\eta))}{1+\bar{r}(1-\bar{h} \eta)}, \beta_{3}=-\frac{\bar{h} g \eta}{1+\bar{r}(1-\bar{h} \eta)} .
$$

Thus, I recover Klein's savings function.

Under uncertainty, the consumption and the savings functions will be nonlinear. Klein's equations may be viewed as the linearized version, and the linear coefficients will be adjusted by presence of risk premium.

Finally, equation (3) can be derived using the endogenous linear relationship between output, consumption, and labor income. It can be viewed as a modification of Klein's wage demand function. Instead of current and lagged output, the labor income given by equation (3) depends on all past output. Furthermore, while the two slope coefficients in Klein's wage demand function are free, coefficients in equation (3) are geometrically declining, controlled by two free parameters. Despite these differences, equation (3) clearly captures the spirit of Klein's wage demand function.

\subsubsection{Cyclic Behavior in the Real Deterministic Economy}

There are two possible interpretations for the constant rate of return $R=\bar{r}+G$. First, one can think of $R$ as the usury rate. For the post war U.S. economy, the average real usury rate is about $0.94 \%$. The average growth rate, $G$, on the other hand, is about $1.89 \%$. It follows 
that $\bar{r}<0$. This implies that, from equation (47) that per capital consumption is in constant decline. This is counter-factual. Second, one can think of $R$ as the average real return on the physical production technology, or aggregate capital stock, or aggregate wealth. For the post war U.S. economy, the average on the aggregate wealth is about $3.1 \%$ (about a third of the average real return on equity), which is larger than the average growth rate. In this case, the economy is capable of delivering a constant, perpetual, per capita consumption for both the capitalist and the worker, which is highly desirable. This is done by choosing model parameters in such a way that $g=1$. The labor contract implies that ratio of the per capita consumptions by the capitalist and the worker in this perpetual state must be $b / \kappa$. Using parameters calibrated by Dai (2000a), $b=0.4176$, and $\kappa=0.0311$, I have $b / \kappa=13.43$. Since the population of the capitalists is much smaller than the population of the workers, the ratio of the consumptions by an average financier and an average laborer is even higher.

Given model parameters, the ratio between per capita physical capital and per capita wage level in the perpetual state can also be computed. An interesting equation is: what would happen if the economy is initiated away from this ratio? Figure 1 shows the behavior of the economy initiated from a recession. The economy is simulated from the calibrated model of Dai (2000a), without the stochastic shocks. ${ }^{18}$ We can see that all four key variables of the economy exhibit the same cyclic behavior, but the fluctuations around the perpetual values die out eventually as the economy converges toward the perpetual state. The cyclic behavior is shown more dramatically in Figure 2, which shows the scatter plots of the per capita wage level vs. either the aggregate consumption per capita or the capitalist's consumption per capita. We can see that the economy converges toward the perpetual state (the center of the attraction) in a counter-clockwise motion.

Thus, unlike real business cycle models of Kydland and Prescott (1982) and Long and Plosser (1983), business cycles in this model is caused entirely by sticky wages, and not by production shocks. This is exactly what Summers (1986) and Mankiw (1989) like to see.

In Section 3, I will show that production shocks (and labor income shocks) help sustain business cycles by preventing the economy from converging to and staying at the perpetual state of constant consumption.

\subsubsection{Relation to Marxian Economics}

Since the heterogenous ownership structure is a cornerstone of Marxian economics, the model laid out in this section should have a very close relationship to Marxian theory. Indeed, the parallel is obvious: the labor income, $x_{t} L_{t}$, can be identified as the "variable capital v", the capitalist's consumption plus investment, $Z_{t}+I_{t}=Y_{t}-x_{t} L_{t}$, can be identified as the "surplus value s", and the physical input, $K_{t}-Z_{t}-x_{t} L_{t}$, can be identified as the "constant capital c".

A crucial assumption by Marx is that the "rate of surplus value",

$$
" s / v "=\frac{Y_{t}-x_{t} L_{t}}{x_{t} L_{t}}=\frac{y_{t}-x_{t}}{x_{t}},
$$

\footnotetext{
${ }^{18}$ We can think of the model discussed in this section as the discrete version of the model of Dai (2000a), when the shocks are turned off. In the limit that the time interval shrinks to 0 , the two models are identical. Thus the behavior of the discrete model is practically the same as those plotted in Figures 1 and 2.
} 
Figure 1: Cyclic Behavior without Shocks
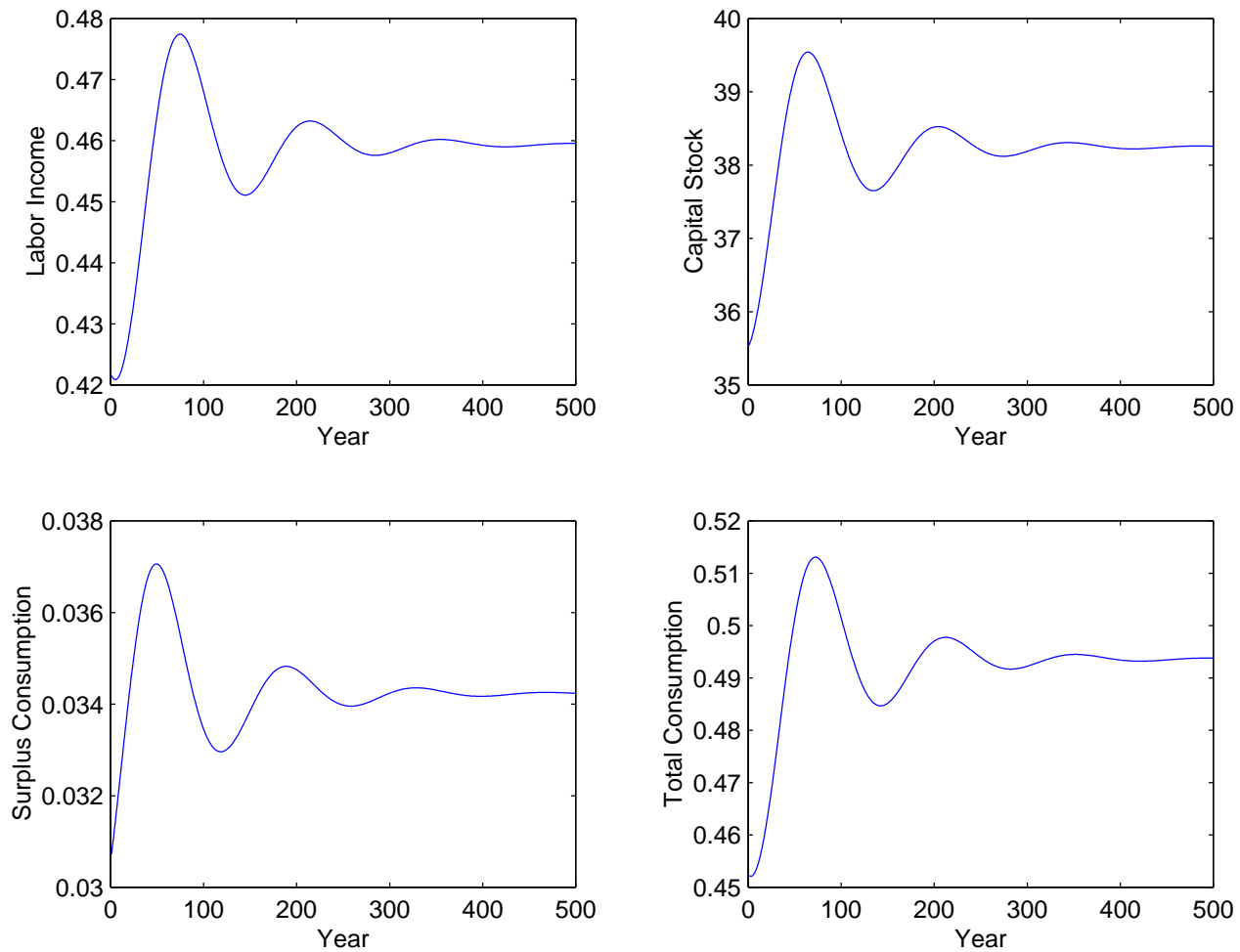

Figure 2: Scatter Plots without Shocks
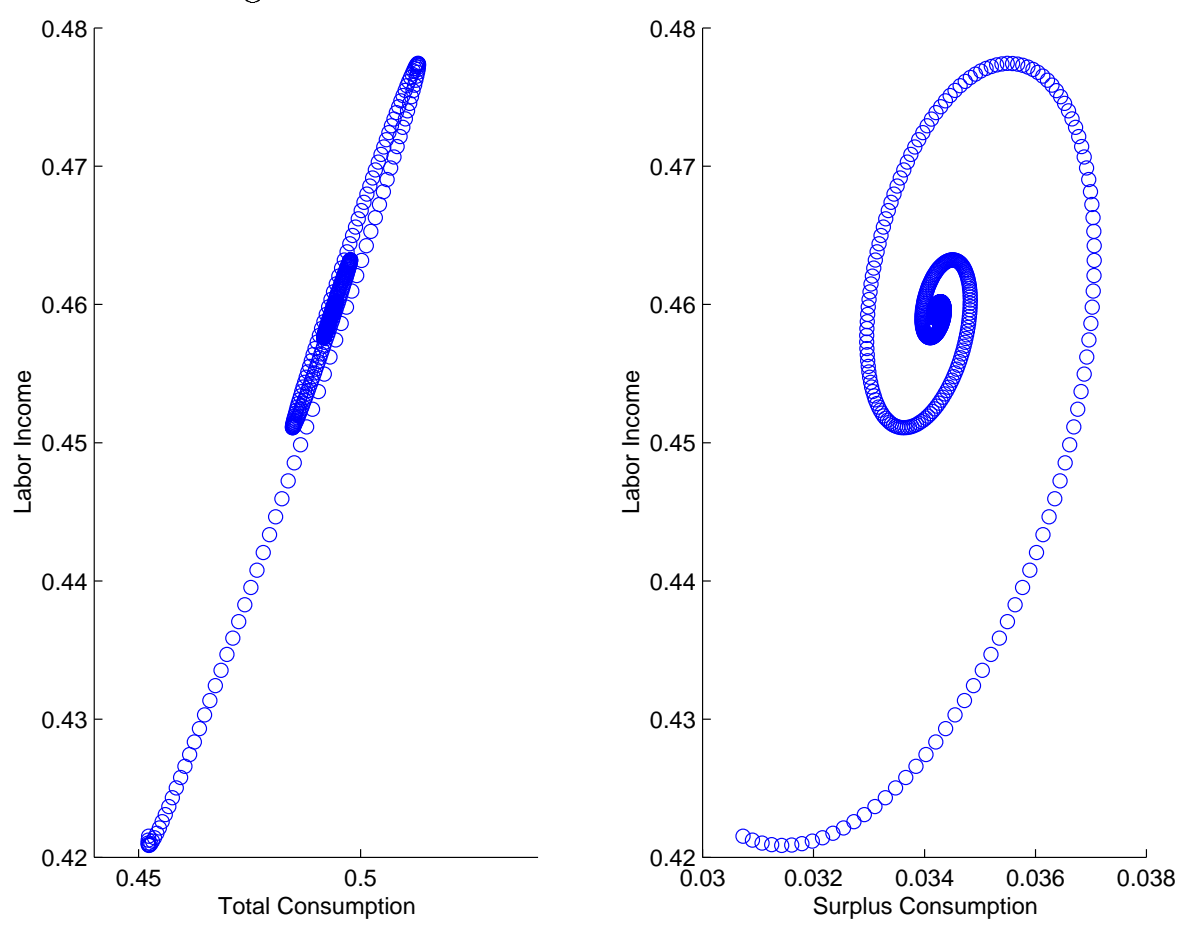
is a constant, and the "organic composition of capital",

$$
\text { "c } c(c+v) "=\frac{k_{t}-z_{t}-x_{t}}{k_{t}-z_{t}},
$$

is rising. This contradicts my model, which implies that

$$
" s / v "=\bar{r}(1-\bar{h}) \frac{k_{t}}{x_{t}}-(1+(1-\bar{h} \eta) \bar{r}),
$$

and

$$
" c /(c+v)^{\prime \prime}=1-\left[(1-\bar{h}) \frac{k_{t}}{x_{t}}+\bar{h} \eta\right]^{-1} .
$$

Note that both "s/v" and "c/(c+v)" depend on the ratio of the physical capital and the labor income, $k_{t} / x_{t}$. Thus, my model predicts that "s/v" is constant if and only if "c/(c+v)" is constant. If " $\mathrm{c} /(\mathrm{c}+\mathrm{v})$ " is rising, which can be caused only by a rising $k_{t} / x_{t}$, "s/v" is necessarily rising (under reasonable assumptions that $\bar{r}>0$ and $\bar{h}<1$ ).

The contradiction between the prediction of my model and the Marxian doctrine is rooted in the issue of income distribution, which is not only an economic problem, but also a political problem. In the formative years of capitalism, it is reasonable for Marx to assume that the capitalist holds monopoly power over the determination of wage rate and prices for consumption goods. ${ }^{19}$ This allows a profit-maximizing capitalist to relentlessly drive down the wage rate, to the point of a severe "economic crisis", and possibly a severe "political crisis" . In my model, however, the labor income (24) gives labor a share of the output in such a way that a steady state of constant consumption and labor income can be achieved (which implies that both "s/v" and "c/(c+v)" reach steady state values.) Since a stable economic growth is clearly desirable for both the the worker and the capitalist ${ }^{20}$, an income distribution represented by the labor contract (24) is an effective remedy to the "economic crises" predicted by Marx - a solution within the capitalist system itself!

The empirical validity of the wage demand captured by (24) has been amply documented, by numerous work of Klein himself and his followers, and is consistent with the emergence of labor unions, the adoption of anti-trust laws, and progressive tax code. This will be further confirmed by Figures 3 and 4 in Section 3.

\section{A Continuous-Time General Equilibrium Model with Production Shocks and Labor Income Risk}

The real world is full of uncertainties, and assets with uncertain payoff demand risk premia. In this section, I consider a model with production shocks and labor income risk that allows us to get a more realistic picture of business cycles and to explain asset returns.

\footnotetext{
${ }^{19}$ Extraction of monopoly rents by capitalists in the consumption goods markets effectively reduces the workers' real purchasing power, and has the same effect of depressing the wage rate, adding to the workers' misery.

${ }^{20}$ Thanks to Marx, the capitalist will eventually realize that an unfair labor contract, such as implicitly assumed by Marx, will lead to less profit and consumption, due to economic and political instability that may result.
} 
I assume that the economy has two production technologies, one riskless, and the other risky. The riskless technology pays a riskless rate $R(t)$. The risky technology pays a dividend rate $D(t)$. The ex-dividend price of the risky technology is $S(t)$. The rate of aggregate output is therefore $Y(t)=d S(t)+D(t) d t$.

At time 0 , the labor contract is given and fixed forever. The capitalist must decide the investment policy, $\alpha(t)$, the fraction of physical capital invested in the risky technology, and the consumption policy, $Z(t)$, the amount of good consumed by the capitalist. The worker consumes the labor income $X(t)$. The aggregate consumption is $C(t) \equiv Z(t)+X(t)$. In equilibrium, the markets for capital goods and consumption goods clear: $\alpha=1$ and $D(t)=C(t)$.

\subsection{Model Assumptions}

Assumption 7 (Aggregate Labor Income) The aggregate labor income, ${ }^{21}$ or cost of labor, is given by

$$
d X(t)=\mu_{X}(X(t), Z(t), t) d t+\sigma_{X}(X(t), Z(t), t) d B_{x}
$$

Furthermore,

- $\frac{\partial \mu_{X}(X, Z, t)}{\partial Z}>0$. This captures the idea that the worker shares the economic prosperity and hardship, but on a delayed basis: high level of consumption by the capitalist does not bring about an immediate increase in the labor income; it raises the growth rate for the labor income. Since the capitalist holds the discretion in terms of real productions, he bears the fruit of economy expansion (or the blunt of economic downturn) more directly than the worker.

- $\frac{\partial \mu_{X}(X, Z, t)}{\partial X}<0$. This captures the idea of mean reversion: if the current wage income is high, the rate of future increase is low or even negative; if the current labor income is low, the rate of future increase is high. This is what drives the economy toward the steady state.

Assumption 8 (Risky Production Technology) The instantaneous total return of the risky production technology is given by

$$
\frac{d S(t)+D(t) d t}{S(t)}=\mu_{S}(S(t), X(t), t) d t+\sigma_{S}(S(t), X(t), t) d B_{s}
$$

Furthermore, the correlation coefficient between $B_{x}$ and $B_{s}$ is an arbitrary constant $\delta$.

As in the deterministic case, I do not impose specific functional forms on the expected return $\mu_{S}$, the conditional volatility $\sigma_{S}$, as well as the riskless rate $R$. At this stage, the production function is completely general (other than the fact that stochastic shocks are introduced as a diffusion).

\footnotetext{
${ }^{21}$ The per capita wage bill is the product of hourly wage and the number of hours employed. We do not need to assume a fixed employment rate, nor a fixed hourly wage.
} 
It is often convenient to introduce a Brownian motion $B_{\perp}$, orthogonal to $B_{s}$, and write

$$
B_{x}=\delta B_{s}+\sqrt{1-\delta^{2}} B_{\perp} .
$$

When $\delta \neq 1$, the labor income risk $B_{x}$ can not be hedged completely by the risky asset. This gives a natural rationale for the existence of a fixed-income contingent claims market. In Appendix C, I show that the existence of a console bond with zero net supply determines the market price of labor income risk.

It is clear that labor income given by (24) is a special case of (60).

The budget constraint of the capitalist under investment policy $\alpha(t)$ and consumption plan $Z(t)$ is given by $^{22}$

$$
d K(t)=\left\{\left[\left(\mu_{S}(t)-R(t)\right) \alpha(t)+R(t)\right] K(t)-Z(t)-X(t)\right\} d t+\alpha(t) K(t) \sigma_{S}(t) d B_{s} .
$$

To close the model, I assume that the capitalist has a time-additive expected power utility function defined over his life-time consumption. That is,

Assumption 9 The capitalist solves

$$
\max _{Z(t) ; 0 \leq t \leq \infty} E\left[\int_{0}^{\infty} e^{-\hat{\rho} s} \frac{Z(s)^{\gamma}}{\gamma} d s \mid K(0)=K_{0}, X(0)=X_{0}\right], \gamma<0,
$$

subject to the budget constraint (63) with labor cost (60), and absence of bankruptcy $(K(t) \geq$ 0 , for $t \geq 0$ ).

\subsection{Relation to Habit Formation Models}

If, in lieu of $Z(t)$, one use the aggregate consumption $C(t) \equiv Z(t)+X(t)$ as the stochastic control, the capitalist's problem can be re-rewritten as

$$
\max _{C(t) ; 0 \leq t \leq \infty} E\left[\int_{0}^{\infty} e^{-\hat{\rho} s} \frac{(C(s)-X(s))^{\gamma}}{\gamma} d s \mid K(0)=K_{0}, X(0)=X_{0}\right]
$$

subject to the budget constraint

$$
d K(t)=\left\{\left[\left(\mu_{S}(t)-R(t)\right) \alpha(t)+R(t)\right] K(t)-C(t)\right\} d t+\alpha(t) K(t) \sigma_{S}(t) d B_{s},
$$

the habit process (60), and absence of bankruptcy $(K(t) \geq 0$, for $t \geq 0)$.

We recognize immediately that, if

$$
\mu_{X}(X, Z, t)=-(a-b) X+b Z+\frac{\epsilon \beta^{2}}{2} Z^{2}, \sigma_{X}(X, Z, t)=\beta Z,
$$

the model is exactly the same as the stochastic habit formation model studied by Dai (2000a) (and by extension Sundaresan (1989) and Constantinides (1990), among others), except for

\footnotetext{
${ }^{22}$ For notational simplicity, I will frequently omit the state variables or stochastic controls in writing down functionals, but will leave the time-dependency, if any, explicit. Thus, $\mu_{S}(t)$ is a shorthand for $\mu_{S}(S(t), X(t), t)$, and and $\sigma_{S}(t)$ is a shorthand for $\sigma_{S}(S(t), X(t), t)$. However, when the functionals depend on only one of the state variables, then I will always make the argument explicit.
} 
the interpretation of $X(t)$. In habit formation models, $X(t)$ is introduced as the consumption habit, an abstract theoretical construct designed to capture the notion of consumption complementarity or time-non-separability of the agent's utility function. In this paper, it is introduced as the aggregate labor income, an observable macro economic variable.

This mapping serves very useful purposes. First, it gives the abstract construct of consumption habit a tangible interpretation. Second, it allows us to use the solution technique of Dai (2000a)to solve the current problem, and derive conditions that restrict the admissible labor contracts. Third, it allows us to derive readily all of the pricing implications of a habit formation model.

The exact mapping implies that the asset pricing problem and the real business cycles problem are completely unified. The solution to the capitalist's problem is the same as the solution to the corresponding asset pricing model.

\subsection{Long-term Growth and Short-term Fluctuations}

It is well documented in the real business cycle literature (see, for example, Hodrick and Prescott (1997)) that the level variables, $S(t), D(t), X(t), Z(t), K(t)$, and $C(t)$ share a common secular trend. Solow (1956), among others, shows that the secular trend is mostly driven by population growth.

Let $H(t)$ be the population of the work force, $G(t)$ be growth rate of $H(t)$, in that

$$
H(t)=H(0) e^{\int_{0}^{t} G(s) d s},
$$

and define per capita variables by

$$
\begin{aligned}
s(t)=S(t) / H(t), & & d(t)=D(t) / H(t), \\
x(t)=X(t) / H(t), & & z(t)=Z(t) / H(t), \\
k(t)=K(t) / H(t), & & c(t)=C(t) / H(t) \\
r(t)=R(t)-G(t), & & \\
\mu_{s}(t)=\mu_{S}(t)-G(t), & & \sigma_{s}(t)=\sigma_{S}(t), \\
\mu_{x}(t)=\mu_{X}(t)-G(t) x(t), & & \sigma_{x}(t)=H(0) / H(t) \sigma_{X}(t)
\end{aligned}
$$

Note that the Sharpe ratio for the risky technology, $\Lambda(t) \equiv \frac{\mu_{S}(t)-R(t)}{\sigma_{S}(t)}=\frac{\mu_{s}(t)-r(t)}{\sigma_{s}(t)}$, is the same for both the original economy and the detrended economy.

It is easy to verify that in terms of per capita variables, we have

$$
\begin{aligned}
d x(t) & =\mu_{x}(t) d t+\sigma_{x}(t) d B_{x} \\
\frac{d s(t)+d(t) d t}{s(t)} & =\mu_{s}(t) d t+\sigma_{s}(t) d B_{s} .
\end{aligned}
$$

The following assumption regulates the per capita economy, so that it is trendless and has a stationary distribution under suitable conditions.

Assumption 10 (Stationarity) $r(t), \mu_{x}(t), \sigma_{x}(t), \mu_{s}(t)$, and $\sigma_{s}(t)$ do not depend on $t$ explicitly, and there are no secular trend in these variables. 
In the remainder of the paper, I will work with the per capita economy, which has no secular trend, but has real fluctuations due to transitory shocks. Our model does not exclude the possibility of permanent shocks in the sense of Campbell and Mankiw (1987b) and Campbell and Mankiw (1987a). Any such permanent shocks can be dealt with by reinterpreting $G(t)$, which may viewed as the portion of the growth rate explained by Solow (1956) and Solow (1957). Through detrending, the short-term dynamics and the long-term dynamics are effectively separated. However, I do not exclude the possibility that the state variables describing business cycles are also, at least partly, responsible for driving the longterm dynamics. For an example, it is perfectly reasonable to assume that the long-term rate $G(t)$ is a function of the detrended (per capita) state variables $k$ and $x$.

\subsection{Admissible Labor Contracts}

Lemma 1 Suppose that labor contracts are specified as an Ito process of the form (70), and the production technology takes the form (71). If we require that, in equilibrium,

1. the riskless rate and the Sharpe ratio depend only on the per capita labor income: $r=r(x), \Lambda=\Lambda(x)$;

2. the indirect utility function be homogeneous in $k-f(x)$ with degree $\gamma$, for some function $f(x)$ satisfying $f(0)=0, f^{\prime}(x)>0$; and

3. the optimal consumption control be proportional to $k-f(x)$, with proportionality constant depends at most on $x$, i.e., $z=h(x)(k-f(x))$;

then, the labor contract must take the following form:

$$
\begin{aligned}
& \mu_{x}(x, z)=l_{0}(x)+l_{1}(x) z+l_{2}(x) z^{2} \\
& \sigma_{x}(x, z)=l_{3}(x) z
\end{aligned}
$$

Proof: Given this labor contract, the capitalist must solve the following Hamilton-JacobianBellman equation:

$$
\begin{aligned}
0 & =\max _{z, \alpha} \frac{z^{\gamma}}{\gamma}-\rho J+\mu_{x}(x, z) J_{x}+\frac{1}{2} \sigma_{x}(x, z)^{2} J_{x x} \\
& +\left(\Lambda(x) \sigma_{s} k+r(x) k-z-x\right) J_{k}+\frac{1}{2} \alpha^{2} \sigma_{s}^{2} k^{2} J_{k k} \\
& +\delta \sigma_{x}(x, z) \sigma_{s} k J_{k x} .
\end{aligned}
$$

In equilibrium, all of the terms must be homogeneous in $k-f(x)$ with degree $\gamma$.

Since $J_{k k}$ is homogeneous in $k-f(x)$ with degree $\gamma-2, z^{\gamma}$ is homogeneous in $k-f(x)$ with degree $\gamma$, and $\alpha=1$ in equilibrium, I conclude that $\sigma_{s} k$ must be homogeneous in $k-f(x)$ with degree 1 . It follows that $\sigma_{x}(x, z)$ must be homogeneous in $k-f(x)$ with degree 1 . Thus, $\sigma_{x}(x, z)$ can be written as

$$
\sigma_{x}(x, z)=l_{3}(x) z=l_{3}(x) h(x)(k-f(x)) .
$$


Since $J_{x x}=\frac{f^{\prime \prime}(x)}{f^{\prime}(x)} J_{x}+\gamma(\gamma-1) f^{\prime}(x)^{2}(k-f(x))^{-2} J$, the first term in $\frac{1}{2} \sigma_{x}(x, z)^{2} J_{x x}$ is homogeneous in $k-f(x)$ with degree $\gamma+1$, and the second term is homogeneous in $k-f(x)$ with degree $\gamma$. The only way to get rid of the inhomogeneous term is to suppose that $\mu_{x}(x, z)$ contains a quadratic term. Since $\mu_{x}(x, z) J_{x}$ itself must be homogeneous in $k-f(x)$ with degree $\gamma, \mu_{x}(x, z)$ can at most be quadratic in $z$. In general, we can write

$$
\mu_{x}(x, z)=l_{0}(x)+l_{1}(x) z+l_{2}(x) z^{2} .
$$

It is easy to check that no other polynomials of $z$ is allowed in $\mu_{x}(x, z)$. The zeroth order term in the above equation introduces a term homogeneous in $k-f(x)$ with degree $\gamma-1$, which gets canceled by a term associated with $J_{k}$, provided that

$$
r(x) f(x)-x-f^{\prime}(x) l_{0}(x)=0,
$$

or

$$
r(x)=\frac{x+f^{\prime}(x) l_{0}(x)}{f(x)} .
$$

Thus, the labor contract completely determines the real riskless rate. ${ }^{23}$ The riskless rate not only depends on the wage level directly, but also depends on the growth rate of the wage level (through $l_{0}(x)$ ). QED.

In the rest of this section, I will assume that the labor contract is given by equation (72), and derive the equilibrium solution to the capitalist problem. The key results are described in the main text, with precise statement of the problem summarized in Appendix A as a proposition and detailed proofs given in Appendices B and C.

\subsection{Optimal Consumption and Portfolio Policies}

I will now derive, analytically, the optimal solution to the capitalist's problem under labor contract

$$
d x=\left(l_{0}(x)+l_{1}(x) z+l_{2}(x)\right) d t+l_{3}(x) d B_{x},
$$

which, when interpreted as the consumption habit, is a generalization of the habit formation model of Dai (2000a). Applying the same solution technique used in Dai (2000a), one can verify that, if

$$
f(x)=\eta \int_{0}^{x} e^{-\int_{0}^{u} \frac{2 l_{2}(v)}{l_{3}(v)^{2}} d v} d u
$$

\footnotetext{
${ }^{23}$ This is another important difference from traditional real business cycle models. In Kydland and Prescott (1982), for an example, the wage rate and employment rate respond to the level of interest rate. In our model, the causality is reversed.
} 
and $h(x)$ and $g(x)$ solve jointly

$$
\begin{aligned}
\frac{h(x)^{\gamma-1}}{\phi} & =\left[1+l_{1}(x) f^{\prime}(x)\right]+(1-\gamma) l_{3}(x)^{2} h(x) f^{\prime}(x)^{2}-\delta l_{3}(x)(1-\gamma) g(x) f^{\prime}(x), \\
0 & =\frac{1-\gamma}{2} g(x)^{2}-\frac{1-\gamma}{\gamma} \delta l_{3}(x) h(x) f^{\prime}(x) g(x)+r(x)-\frac{\rho}{\gamma} \\
& +\frac{1-\gamma}{\gamma}\left[1+l_{1}(x) f^{\prime}(x)\right] h(x)+\frac{(1-\gamma)(2-\gamma)}{2 \gamma} l_{3}(x)^{2} h(x) f^{\prime}(x)^{2},
\end{aligned}
$$

then

1. The riskless rate is given by

$$
r(x)=\frac{x+f^{\prime}(x) l_{0}(x)}{f(x)} .
$$

2. The Sharpe ratio is given by

$$
\Lambda(x)=(1-\gamma)\left[g(x)-\delta l_{3}(x) h(x) f^{\prime}(x)\right] .
$$

3. The optimal portfolio weight is given by

$$
\alpha^{*}=\frac{g(x)}{\sigma_{s}} \frac{k-f(x)}{k} .
$$

4. The optimal consumption by the capitalist is given by

$$
z^{*}=h(x)(k-f(x)) .
$$

Furthermore, under the market clearing conditions

$$
\alpha^{*}=1, z^{*}+x=d
$$

I obtain, in equilibrium,

$$
k^{*}=s,
$$

and

$$
\sigma_{s}=\frac{k-f(x)}{k} g(x)=\frac{s-f(x)}{s} g(x) .
$$

Note that the optimal solution depends directly on all four functions: $l_{i}(\cdot), i=0,1,2,3$, that characterize the labor contract. It is easy to check that when

$$
l_{0}(x)=-(a-b) x, l_{1}(x)=b, l_{2}(x)=\frac{\epsilon \beta^{2}}{2}, l_{3}(x)=\beta,
$$

where $a, b, \beta$, and $\epsilon$ are constants, ${ }^{24}$ the resulting labor income corresponds exactly to the stochastic habit process of Dai (2000a), and the optimal solution to the capitalist's problem is identical to the optimal solution of Dai (2000a)'s model.

\footnotetext{
${ }^{24}$ This $\beta$ is different from the $\beta$ used in Section 2 .
} 


\subsection{Pricing Kernel (with Production and Labor Income Risks)}

Similar to Dai (2000a), I can assume that there exists a fixed-income contingent claims market. In particular, I assume that there exists a console bond with zero supply, which can be used to hedge against the wage shocks. This completes the market. The pricing kernel can be derived, in a completely analogous fashion to Dai (2000a), and is given by (the derivation is given in Appendix $\mathrm{C}$ ):

$$
\frac{d m(t)}{m(t)}=-r(x) d t-\Lambda(x) d B_{s}-\Lambda_{\perp}(x) d B_{\perp}
$$

where $r(x)$ and $\Lambda(x)$ are given earlier and

$$
\Lambda_{\perp}=-(1-\gamma) \sqrt{1-\delta^{2}} l_{3}(x) h(x) f^{\prime}(x) .
$$

The pricing kernel in the original economy is simply

$$
\frac{d M(t)}{M(t)}=-(r(x(t))+G(t)) d t-\Lambda(x(t)) d B_{s}-\Lambda_{\perp}(x(t)) d B_{\perp},
$$

obtained from the fact that $M(t)=m(t) e^{\int_{0}^{t} G(s) d s}$.

\subsection{Determinants of Human Capital}

Now that I have the pricing kernel, I can derive the value of the human capital given a labor contract. Let $n(t)=N(t) e^{-\int_{0}^{t} G(s) d s}$, I have

$$
\begin{aligned}
n(k, x) & =E\left[\int_{t}^{\infty} x(s) m(s) d s \mid k(t)=k, x(t)=x\right] \\
& =E^{Q}\left[\int_{t}^{\infty} x(s) \hat{m}(s) d s \mid k(t)=k, x(t)=x\right],
\end{aligned}
$$

where $Q$ is the risk-neutral measure, and $\hat{m}(t)$ is the pricing kernel under $Q$, namely,

$$
\frac{d \hat{m}}{\hat{m}}=-r(t) d t
$$

Applying the Feynman-Kac theorem, $n(t)$ is determined by the following PDE:

$$
\begin{gathered}
\hat{\mu}_{x} n_{x}+\frac{1}{2} l_{3}(x)^{2} h(x)^{2}(k-f(x))^{2} n_{x x} \\
+\hat{\mu}_{k} n_{k}+\frac{1}{2} g(x)^{2}\left(\frac{k-f(x)}{k}\right)^{2} n_{k k}-r(x) n(k, x)+x=0,
\end{gathered}
$$

with the boundary conditions $n(k, 0)=0$ and $n(0, x)=0 . \hat{\mu}_{x}$ and $\hat{\mu}_{k}$ in the above equation are the risk-neutral drift of the labor income and the expected return to capital, respectively. Applying Girsanov's theorem, I have

$$
\begin{aligned}
\hat{\mu}_{x} & =\mu_{x}-l_{3}(x) z\left[\delta \Lambda(x)+\sqrt{1-\delta^{2}} \Lambda_{\perp}(x)\right] \\
& =l_{0}(x)+\hat{l}_{1}(x) z+l_{2}(x) z^{2}
\end{aligned}
$$


where $z=z(k, x)=h(x)(k-f(x))$, and

$$
\hat{l}_{1}(x)=l_{1}(x)-(1-\gamma) l_{3}(x)\left[\delta g(x)-l_{3}(x) h(x) f^{\prime}(x)\right] .
$$

Furthermore,

$$
\hat{\mu}_{k}=\mu_{s} k-z-x-\sigma_{s} \Lambda(x)=r(x) k-z(k, x)-x .
$$

Thus, the human capital can, in principle, be determined, and is, in general, a nonlinear function of $k$ and $x$. However, since both the labor income $x$ and the optimal consumption $z$ are nonlinear processes, it is difficult to derive an analytical expression for $n(k, x)$.

Instead of solving $n(k, x)$ directly from the PDE, one can characterize it in terms of $k$ and $f(x)$. Think of $f(x)$ as the price of a security that pays a dividend $\phi(k, x)$, that is,

$$
f(x)=E^{Q}\left[\int_{t}^{\infty} \phi(k(s), x(s)) e^{-\int_{t}^{s} r(u) d u} d s \mid k(t)=k, x(t)=x\right] .
$$

Feynman-Kac theorem implies

$$
\phi(k, x)=-\left[\hat{\mu}_{x} f^{\prime}(x)+\frac{1}{2} l_{3}(x)^{2} z^{2} f^{\prime \prime}(x)-r(x) f(x)\right]=x-\hat{l}_{1}(x) f^{\prime}(x) z,
$$

where I have used the fact that

$$
f^{\prime}(x) l_{0}(x)=r(x) f(x)-x, f^{\prime \prime}(x)=-\frac{2 l_{2}(v)}{l_{3}(v)^{2}} f^{\prime}(x) .
$$

Thus,

$$
\begin{aligned}
f(x) & =E^{Q}\left[\int_{t}^{\infty}\left[x(s)-\hat{l}_{1}(x(s)) f^{\prime}(x(s)) z(s)\right] \hat{m}(s) d s \mid k(t)=k, x(t)=x\right] \\
& =E\left[\int_{t}^{\infty}\left[x(s)-\hat{l}_{1}(x(s)) f^{\prime}(x(s)) z(s)\right] m(s) d s \mid k(t)=k, x(t)=x\right]
\end{aligned}
$$

Since the physical capital is equal to the market value of all future consumption,

$$
k=E\left[\int_{t}^{\infty}(z(s)+x(s)) m(s) d s \mid k(t)=k, x(t)=x\right]
$$

I have

$$
k-f(x)=E\left[\int_{t}^{\infty}\left[1+\hat{l}_{1}(x(s)) f^{\prime}(x(s))\right] z(s) m(s) d s \mid k(t)=k, x(t)=x\right],
$$




\subsubsection{A Special Case: Risky Production and Deterministic Labor Income}

Suppose that the labor contract is given by

$$
d x=(b z-(a-b) x) d t,
$$

where $a>b>0$ are constants. This is the continuous-time version of the model in Section 2 plus production shocks.

With production shocks, the riskless rate in this model need not be constant. The reason is that the risk premium for the risky technology will enter a generalized version of equation (42), which becomes an endogenous restriction on the relationship between the risk premium and the riskless rate, in the spirit of Cox et al. (1985). Unlike Cox et al. (1985), however, the riskless rate in this model is determined by the continuous-time version of equation (41). With the absence of labor income risk, however, the model does not impose any restriction on the functional form of $f(x)$, other than the requirement that $f(0)=0$ and $f^{\prime}(x)>0$. Thus, there is an infinite class of solutions to the model with risky production and deterministic labor contract, corresponding to an arbitrary choice of $f(x)$. Dai (2000a) shows that the riskless rate and the Sharpe ratio of the risky technology are constant, whenever $f(x)$ is linear. Furthermore, the riskless rate and the Sharpe ratio are state-dependent, whenever $f(x)$ is nonlinear.

For illustrative purpose, let us focus on the solution that characterizes an economy with constant riskless rate and Sharpe ratio. This economy is observationally equivalent to the economy in Constantinides (1990), with a linear $f(x)$, which can be written as $f(x)=\eta x$. Equation (41) implies that $\eta=\frac{1}{r+a-b}>0$.

In this case, equation (103) implies

$$
\frac{k-f(x)}{1+b \eta}=E\left[\int_{t}^{\infty} z(s) m(s) d s \mid k(t)=k, x(t)=x\right] .
$$

It follows that

$$
n(k, x)=k-\frac{k-f(x)}{1+b \eta}=\frac{b k+x}{r+a} .
$$

That is, the human capital is linear in both the physical capital and the current labor income. Given the physical capital and the labor income, a higher $b$, a lower $a$, or a lower $r$ imply a higher human capital.

At a given level of consumption $z$, a bigger $b$ means the labor cost increases at a higher rate, giving the worker a higher share of the output. This explains why, for a given level of physical capital and wage level, a higher $b$ leads to a higher human capital/physical capital ratio.

$b$ is important for another reason: faster rate of wage increases tend to hasten the arrival of economic downturn. Thus, other things equal, an economy with a higher $b$ tends to have less severe, but more frequent, business cycles. This prediction of the model appears to be consistent with historical experiences. In the early stage of the capitalist economies, when the workers' rights are relatively few and their compensation are relatively insensitive to production gains and technological advances, the economic expansions tended to last 
longer, but the downturns also tended to be more severe and protracted. As the workers' rights improve through unionization and legislation, business cycles become more frequent and less severe. The long economic expansion we witness today does not contradict this view of events, because rapid technological advances tend to increase the value of physical capital and reduce the value of human capital as a share of the physical capital. If recent technological advances take hold, it is likely that labor contract will eventually be adjusted to reflect the prevailing sense of social and economic justice and the workers' bargaining power. In another word, we would expect $b$ to increase.

Of particular interest is the fact that, with the physical capital and labor contract (including current wage level) fixed, lowering the real riskless rate has the effect of raising the human capital. In another word, real interest rate is an instrument of income redistribution!

This help explain the role of central bank intervention in managing business cycles. In a recession, central bank injects liquidity into the economy, effectively lowering the riskless rate. This has the effect of increasing the welfare of the worker. But wait, there appears to be a contradiction. According to our model, lowering interest rate increases the human capital and therefore the welfare of the worker, but it also decreases the capitalized value of the capitalist's consumption, and therefore the welfare of the capitalist. On the other hand, a common perception is that the capitalist is benefited by a lower interest rate because, with a lower borrowing cost, the production is more profitable.

The contradiction is resolved by noting that our model does not explicitly incorporate the role of the central bank, and therefore in itself, does not provide a facility for adjusting interest rate and effecting income redistribution. However, the role of the central bank can be understood intuitively. By lowering the riskless rate during a recession, the central bank increases the welfare of both the capitalist and the worker, at the expense of the government treasury: the treasury's lending to the business at a rate lower than the current market rate increases the capitalist's profit and encourages economic expansion. Part of the welfare gain to the capitalist is shifted to the worker through income redistribution caused by the reduction in the riskless rate. The cost to the treasury can be recuperated from taxation or from future rate hikes, when the economy is booming. Taxation and rate hike puts a break on the expansion of the economy, but the welfare reduction is more tolerable. Thus, the central bank can effectively smooth out business cycles and fluctuations in welfare.

The same story goes through if everything is in nominal terms. This would explain why inflation reduces welfare: it reduces the debt burden of the treasury at the expense of both the capitalist and the worker: the worker's welfare is reduced partly because the value of its human capital is reduced; the capitalist's welfare is reduced because of higher borrowing cost and reduced profit. In all of this, the rigidness of the labor contract plays an essential role - the Keynesian perspective comes through, loud and clear.

\subsubsection{Another Special Case: Stochastic labor Contract}

Suppose that the labor contract is given by

$$
d x=\left[b z+\frac{\epsilon \beta^{2}}{2} z^{2}-(a-b) x\right] d t+\beta z d B_{x}
$$


where $a>b>0, \epsilon>0, \beta>0$, and $\delta=\operatorname{corr}\left(B_{x}, B_{s}\right)<0$. This corresponds to the stochastic habit formation model of Dai (2000a). In this case, analytical expression of human capital is not available. However, qualitative properties can be gleaned from the behavior of the optimal solution.

Unlike the deterministic case, the model now provides an endogenous mechanism to achieve income redistribution. One can show that, under quite general conditions, the riskless rate is monotonically increasing with the labor income (see Section 3.8.) This implies that in recessions, when the labor income is relatively low, the value of human capital, as a share of the physical capital, will not be as low as if the riskless rate were constant. In booms, when the labor income is relatively high, the value of human capital, as a share of the physical capital, will not be as high as if the riskless rate were constant. In another word, a pro-cyclic riskless rate helps smooth the fluctuations in the worker's welfare.

The cyclic behavior of the economy under labor contract (107) is best illustrated by showing the scatter plot of aggregate labor income and aggregate consumption. Figure 3 is such a plot using data simulated from the model (using parameter calibrated by Dai (2000a)), and Figure 4 is the same plot using observed labor income and consumption data (post war U.S.). The two plots share a striking similarity in the two dimensional structure. Cyclicality is not as apparent as Figure 2, but I can verify that in both the simulated and the observed cases, the economy moves in a counter-cyclic motion, aside from small fluctuations.

The lower half of the two-dimensional structure represents the expansion phase of the economy, characterized by increasing consumption and labor cost. The upper half represents the contraction phase of the economy, characterized by declining consumption and labor cost. The expansion phase comes to an end when the labor cost becomes too high, and the recession comes to an end when the labor cost is sufficiently low. In the middle of an expansion, the economy does not slow down even though the aggregate consumption is near its steady state value because the labor cost is lower than its steady state value. Similarly, in the middle of a contraction, the economy is not ready to recover because the labor cost is still higher than its steady state value.

\subsection{Labor Contracts with Pro-cyclic Riskless Rate}

Pro-cyclic riskless rate is desirable from the worker's point of view because it reduces the impact of business fluctuations. The capitalist is happy to accommodate, because he is suitably compensated. A natural question is: under what conditions a general admissible labor contract of the form (72) gives rise to a pro-cyclic riskless rate?

To answer this question, let $F_{1}(x)=f(x)-x f^{\prime}(x)$, and $F_{2}(x)=l_{0}^{\prime}(x) f(x)-\frac{2 l_{2}(x)}{l_{3}(x)} f(x)-$ $l_{0}(x) f^{\prime}(x)$. It is easy to show that

$$
r^{\prime}(x)=\frac{F_{1}(x)+F_{2}(x) f^{\prime}(x)}{f(x)^{2}} .
$$

A pro-cyclic riskless rate implies $r^{\prime}(x) \geq 0$. Since $f^{\prime}(x)>0$, it is sufficient that $F_{1}(x) \geq 0$ and $F_{2}(x) \geq 0$. It is easy to show that $F_{1}(x) \geq 0: F_{1}(0)=0$, and $F_{1}^{\prime}(x)=-x f^{\prime \prime}(x)>0$. For $F_{2}(x) \geq 0$, note that $F_{2}(0)=-l_{0}(0) f^{\prime}(0)$, and $F_{2}^{\prime}(0)=\left[l_{0}^{\prime}(x)-\frac{2 l_{0}(x) l_{2}(x)}{l_{3}(x)}\right]^{\prime} f(x)$. Thus, 
Figure 3: Consumption vs. Habit: with Simulated Production Shocks

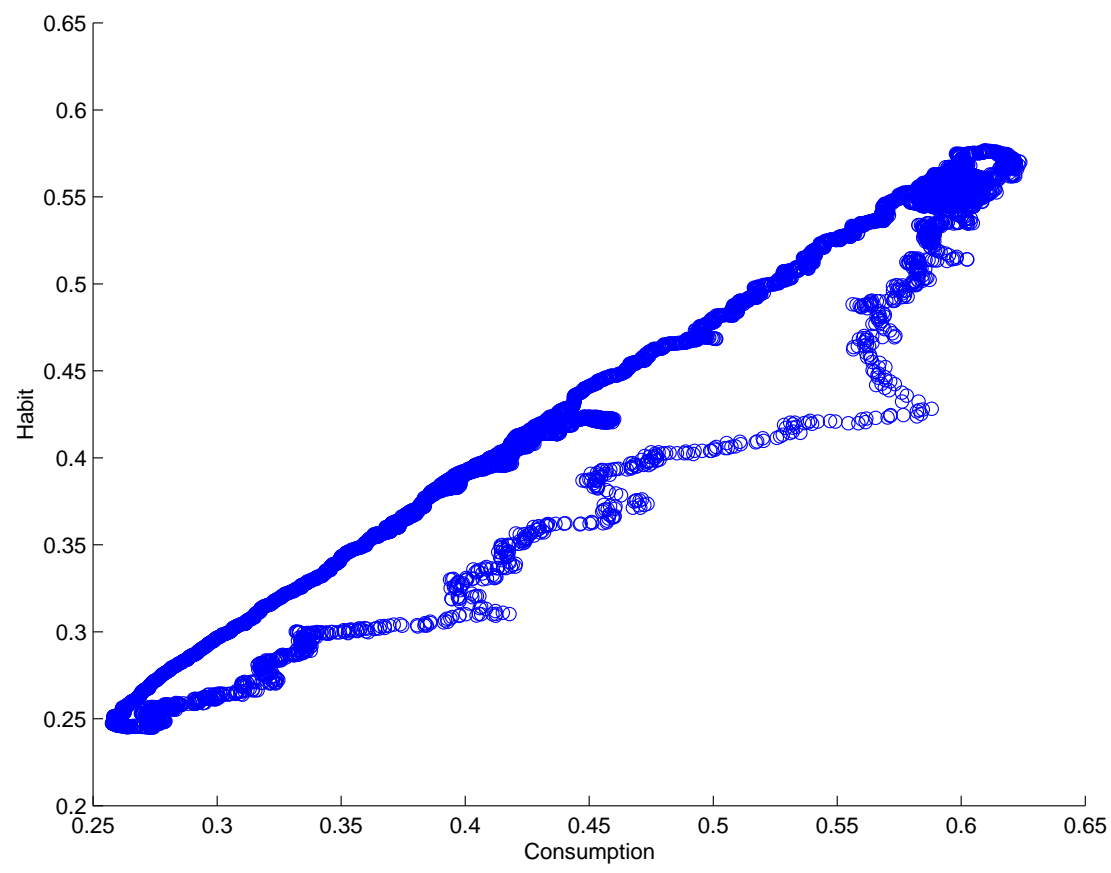

Figure 4: Consumption vs. Labor Cost: From Data

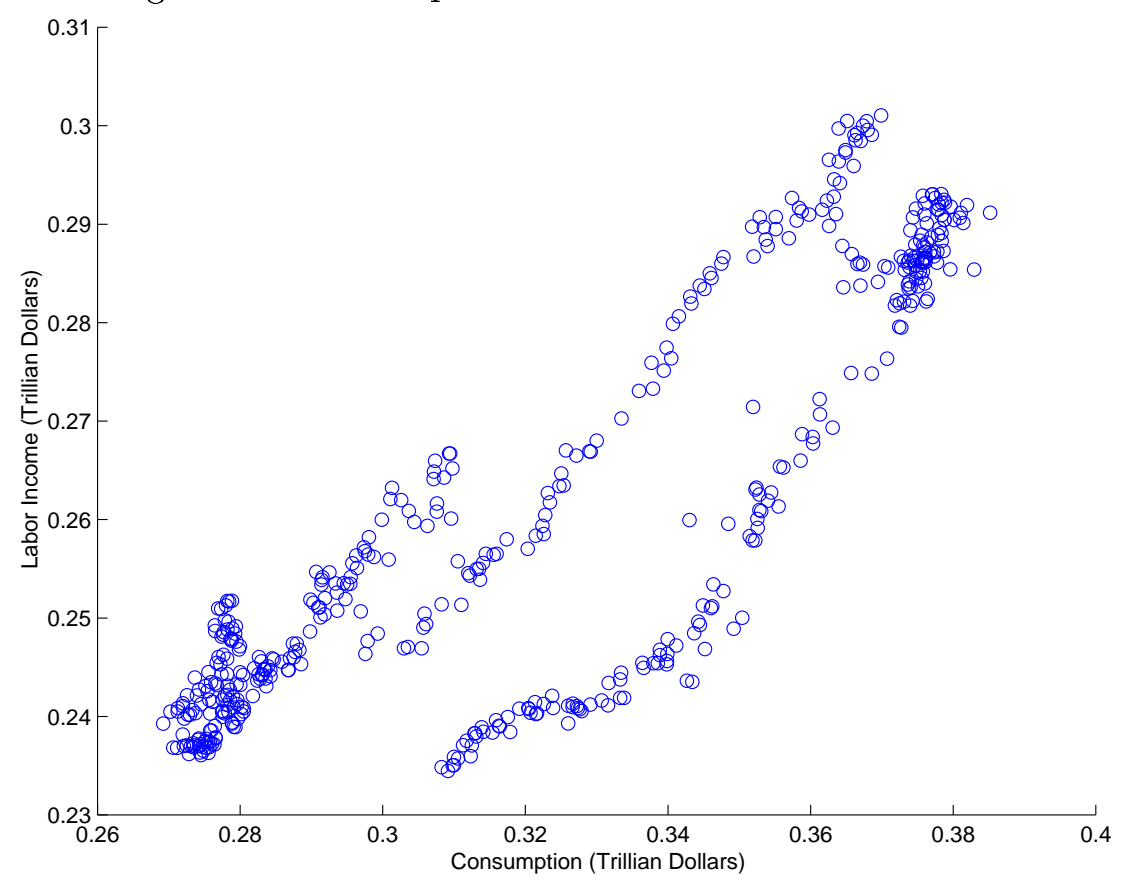


for $F_{2}(x)>0$, it is sufficient that $l_{0}(0) \leq 0$, and $l_{0}^{\prime}(x)-\frac{2 l_{0}(x) l_{2}(x)}{l_{3}(x)}$ is increasing in $x$. For the labor contract (107), these conditions are satisfied.

\section{A Two-factor Capital Asset Pricing Model with Hu- man Capital}

Our model has natural implications for the capital markets behavior. In this section, I show how to construct a two-factor Capital Asset Pricing Model under some simplifying assumptions about individual firms' dividend policies and labor costs.

\subsection{Defining Returns}

Let us begin by defining three concepts of returns. To help illustrate the ideas, let us motivate the definition using the discrete-time formulations, then take the limit to get the continuoustime version. If we treat the model as a description of a firm, the stock of physical capital, $K_{t}$, at the beginning of period $t$, can be thought of as the cum-dividend stock price. The dividend to the equity holder is simply $Z_{t} d t$. Thus, the ex-dividend equity price is $K_{t}-Z_{t} d t$. The physical input used for production has a value of $K_{t}-Z_{t} d t-X_{t} d t$. The three definitions are summarized below.

\begin{tabular}{l|l|l}
\hline Name & Discrete-time & Continuous-time \\
\hline Return to Capital & $R_{t}^{c} \equiv \frac{K_{t+d t}}{K_{t}-Z_{t} d t-X_{t} d t}-1$ & $\frac{d K_{t}+Z_{t} d t+X_{t} d t}{K_{t}}$ \\
Return to Equity & $R_{t}^{e} \equiv \frac{K_{t+d t}}{K_{t}-Z_{t} d t}-1$ & $\frac{d K_{t}+Z_{t} d t}{K_{t}}$ \\
Net Capital Gain & $R_{t}^{g} \equiv \frac{K_{t+d t}}{K_{t}}-1$ & $\frac{d K_{t}}{K_{t}}$ \\
\hline
\end{tabular}

Under general conditions, we have $Z_{t} \geq 0, X_{t} \geq 0, K_{t}-Z_{t} d t-X_{t} d t>0$. It follows that

$$
R_{t}^{g} \leq R_{t}^{e} \leq R_{t}^{c}
$$

The return to equity is larger than the net capital gain, because the equity holder receives dividend income. The return to capital, whose conditional mean is $\mu_{S}$ in the continuous-time formulation, is larger than the equity return, because it captures both the dividend income and the labor income. In continuous-time, the expected equity return is the expected return to capital minus the labor income/aggregate wealth ratio, and the expected rate of capital gain is the expected return to capital minus the consumption/wealth ratio, or the expected return to capital minus the dividend/price ratio. In the postwar U.S. economy, the expected return to equity is about $7.85 \%$. Suppose that the dividend/price ratio is about $1 \%$, then labor income/price ratio is about $4 \%$ (labor income is about four times of financial income), Consequently, the expected return to capital is about $11.85 \%$. Since the conditional volatility of the all three returns are the same, let us assume that the unconditional volatility are also roughly the same (about $15.92 \%$ for equity returns). It follows that the Sharpe ratio based on the return to capital is $\frac{11.85 \%-0.94 \%}{15.92 \%}=0.6853$, while the Sharpe ratio based on the return to equity is $\frac{7.85 \%-0.94 \%}{15.92 \%}=0.4341$. The difference between these two Sharpe ratios is not a diversification effect. Instead, it is an issue of basic accounting: the return to human capital 
should be included in the return to capital or aggregate wealth, but is excluded in the return to equity.

The distinction of these different concepts of return is important for linking the model to empirical observations. The equity pricing literature has traditionally and almost exclusively used the return to equity to measure the value of a stock, which is perfectly fine. Confusion arises when the equity return is mistaken for return to capital. Let us give two examples.

First, many financial economists find the low correlation between equity return and aggregate consumption puzzling. From the above discussion, it is clear that it need not be a puzzle at all. Since the equity return does not account for labor income, which is a big chunk (about $80 \%$ in the U.S.) of the aggregate consumption, there is no reason to expect that the equity return and the aggregate consumption be highly correlated. We can, however, expect that (1) the aggregate consumption is strongly correlated with the expected return to capital; and (2) the surplus consumption, which is the difference between the aggregate consumption and labor income, is strongly correlated with the expected return to equity. The latter is precisely what habit formation models capture once we equate labor income with consumption habit.

Second, Campbell (1999) finds the high volatility of equity return to be puzzling. Dai (2000a) shows that it need not be puzzling, if we make a proper distinction between the return to capital and the return to equity.

\subsection{Pricing Equities}

Suppose that a firm $j$ pays a per capita dividend stream $z_{t}^{j}$, and its labor cost is given by $x_{t}^{j}$. Consider a simple case where the dividend/price ratio $z_{t}^{j} / k_{t}^{j}$ and the wage/price ratio $x_{t}^{j} / k_{t}^{j}$ are functions of per capita aggregate wealth $k_{t}$ and per capita aggregate labor income $x_{t}$ only. Then the per capita equity price, $k_{t}^{j}$ is also a function of $k_{t}$ and $x_{t}$ only, given by ${ }^{25}$

$$
k_{t}^{j}=\frac{1}{m(t)} E\left[\int_{t}^{\infty}\left(\frac{z_{s}^{j}}{k_{s}^{j}}+\frac{x_{s}^{j}}{k_{s}^{j}}\right) k_{s}^{j} m_{s} d s \mid k(t)=k, x(t)=x\right] \text {. }
$$

Ito's lemma implies

$$
\frac{d k_{t}^{j}}{k_{t}^{j}}=\mu_{j} d t+\sigma_{j s} d B_{s}+\sigma_{j \perp} d B_{\perp},
$$

${ }^{25}$ The common notion that the equity price is the capitalized value of the dividend income is correct only if the dividends are discounted by the expected return to equity, rather than the expected return to capital. It is important to note that the price of a stock with dividend stream $z_{t}^{j}$ is not given by

$$
k_{t}^{j}=E_{t}\left[\int_{t}^{\infty} z_{s}^{j} \frac{m(s)}{m(t)} d s\right]
$$

where $m(t)$ is the pricing kernel given by (89). 
where

$$
\begin{aligned}
\mu_{j} & =\frac{\partial k_{t}^{j}}{\partial t}+\mathcal{A} k_{t}^{j}(k, x), \\
\sigma_{j s} & =g(x)(k-f(x)) \frac{\partial k_{t}^{j}}{\partial k}+\delta l_{3}(x) h(x)(k-f(x)) \frac{\partial k_{t}^{j}}{\partial x}, \\
\sigma_{j \perp} & =\sqrt{1-\delta^{2}} l_{3}(x) h(x)(k-f(x)) \frac{\partial k_{t}^{j}}{\partial x}
\end{aligned}
$$

where $\mathcal{A}$ is the infinitesimal generator.

In equilibrium, $k_{t}^{j} m_{t}+\int_{0}^{t}\left(z_{s}^{j}+x_{s}^{j}\right) m_{s} d s$ must be a Martingale. It follows that the expected excess return to capital is

$$
r_{t, j}^{c} \equiv \mu_{j}+\frac{z_{t}^{j}}{k_{t}^{j}}+\frac{x_{t}^{j}}{k_{t}^{j}}-r_{t}=\Lambda(x) \sigma_{j s}+\Lambda_{\perp}(x) \sigma_{j \perp} .
$$

This is a partial differential equation that determines the equity price $k_{t}^{j}$. In principle, it can be solved numerically.

Equation (114) implies that the equity premium, i.e., expected excess return to equity, is given by

$$
r_{t, j}^{e} \equiv \mu_{j}+\frac{z_{t}^{j}}{k_{t}^{j}}-r_{t}=\Lambda(x) \sigma_{j s}+\Lambda_{\perp}(x) \sigma_{j \perp}-\frac{x_{t}^{j}}{k_{t}^{j}},
$$

Note that the equity premium depends explicitly on the wage/price ratio. This explains why corporate down-sizing has an immediate effect on a firm's bottom line.

Equation (115) is a two-factor, continuous-time version of the conditional, consumption based, capital asset pricing model (CAPM), in the tradition of Sharpe (1964), Lintner (1965), Merton (1973), and Breeden (1979). The CAPM derived from our model is a special case of multi-factor CAPM of Merton (1973). However, the state variables in our model are readily identified as the physical capital (or capitalist's consumption) and labor income (or human capital).

To express our CAPM in the familiar beta form, define $r_{t, M}^{e}$ as the expected return on the stock market portfolio, which consists of $\alpha_{j}$ share of stock $j$, for $j=1,2, \cdots, N$. Multiplying both sides of (115) by $\alpha_{j}$ and summing over all stocks, I have

$$
r_{t, M}^{e}=\Lambda(x) \sum_{j=1}^{N} \sigma_{j s}+\Lambda_{\perp}(x) \sum_{j=1}^{N} \sigma_{j \perp}-\sum_{j=1}^{N} \frac{x_{t}^{j}}{k_{t}^{j}} .
$$

It follows that

$$
r_{t, j}^{e}=\beta_{j M}(k, x) r_{t, M}^{e}
$$

where

$$
\beta_{j M}(k, x)=\frac{\Lambda(x) \sigma_{j s}+\Lambda_{\perp}(x) \sigma_{j \perp}-\frac{x_{t}^{j}}{k_{t}^{j}}}{\Lambda(x) \sum_{j=1}^{N} \sigma_{j s}+\Lambda_{\perp}(x) \sum_{j=1}^{N} \sigma_{j \perp}-\sum_{j=1}^{N} \frac{x_{t}^{j}}{k_{t}^{j}}} .
$$


Instead of a two-dimensional security market hyperplane, we still have a one-dimensional security market line. The two-factor structure enters through the state-dependency of $\beta_{j M}(k, x)$.

When the market is complete (the existence of a console bond suffices), the three-fund separation theorem of Merton (1973) obtains. From Appendix A, the expected return on the console bond is given by

$$
r_{t, p}^{e} \equiv \mu_{p}-r=-\sigma_{p} \delta_{p} \Lambda(x)-\sigma_{p} \sqrt{1-\delta_{p}^{2}} \Lambda_{\perp}(x) .
$$

Because there are only two state variables, the expected return on an arbitrary security $j$ is completely determined once the expected returns on the stock market portfolio and the console bond are known. When the expected returns are approximately linear in the state variables, the familiar security market hyperplane obtains: let $\bar{\beta}_{j M}$ and $\bar{\beta}_{j p}$ be the linear projection coefficients of $r_{t, j}^{e}$ onto $r_{t, M}^{e}$ and $r_{t, p}^{e}$, I have

$$
r_{t, j}^{e} \approx \alpha_{j}+\bar{\beta}_{j M} r_{t, M}^{e}+\bar{\beta}_{j p} r_{t, p}^{e}
$$

Even though the second portfolio is the bond portfolio, it arises because of the need to hedge labor income risk, and is related to the expected return to human capital. Since the value of human capital is not observed, while bond returns are observed, the two-factor CAPM (120) is more useful for empirical tests than a model expressed in terms of the aggregate market return and the aggregate return to human capital.

In the above derivation, I made a simplifying assumption that a firm's dividend/price ratio and wage/price ratio are determined entirely by the aggregate wealth and aggregate labor cost. As a zeroth order approximation, this may not be a bad assumption. However, in specifying the dividend/price and wage/price ratios for individual stocks, one must make sure that they do not lead to inconsistencies upon aggregation (e.g., $k$ must the sum of all individual equity prices.)

To treat the pricing of multiple risky assets properly, we need to extend our model to a situation, where the capitalist can invest in multiple firms, with each negotiating its own labor cost with its workers and setting its own optimal dividend policy. This is important for two reasons. First, there are idiosyncratic variations in individual firms' dividend policies and labor costs (mostly due to the nature of the production technology it employs), so that the cross-sectional variations in equity premium may not be completely explained by two aggregate factors. ${ }^{26}$ Second, and more importantly, optimal asset allocation and market clearing conditions can impose important endogenous restrictions on the returns and dividend policies that must be taken into account in dealing with multiple risky assets simultaneously (e.g., in portfolio analysis). This extension will be examined elsewhere.

\footnotetext{
${ }^{26}$ For an example, the dividend policy and the structure of labor cost of growth firms are likely to be quite different from those of value companies. Consequently the aggregate market return and the aggregate return to human capital may not explain all of the growth/value premium.
} 


\section{$5 \quad$ Structural Link between the Macroeconomy and the Term Structure of Real Interest Rates}

Another implication of our model is that the aggregate consumption and labor income determine the term structure of real interest rates. This provides a structural link between the macroeconomy and the term structure of real interest rates.

Let $p_{T}$ and $y_{T}=-\frac{1}{T} \log P_{T}$ be the price and yield, respectively, of a zero coupon bond with par of $\$ 1$ and maturity of $T$ years. In general, both $p_{T}$ and $y_{T}$ are functions of the two state variablesr and $z{ }^{27} \mathrm{I}$ define the loadings of $y_{T}$ on the state variables by

$$
b_{r}(T)=\frac{\partial y_{T}}{\partial r}, \quad b_{z}(T)=\frac{\partial y_{T}}{\partial \log z}
$$

Since $y_{0} \equiv r$, it is necessarily the case that $b_{r}(0)=1$ and $b_{z}(0)=0$.

Using Ito's lemma, the stochastic development of $p_{T}$ can be written as ${ }^{28}$

$$
\begin{aligned}
\frac{d p_{T}}{p_{T}} & =\mu_{p} d t+\frac{\partial \log p(r, z)}{\partial \log z}\left(\sigma_{z s}(x) d B_{s}+\sigma_{z x}(x) d B_{x}\right)+\frac{\partial \log p(r, z)}{\partial r} \sigma_{r}(x) d B_{x} \\
& =\mu_{p} d t-\sigma_{p}\left(\delta_{p} d B_{s}+\sqrt{1-\delta_{p}^{2}} d B_{\perp}\right)
\end{aligned}
$$

where

$$
\begin{aligned}
\delta_{p}=-\frac{\sigma_{p s}}{\sigma_{p}}, & \sigma_{p}=\sqrt{\sigma_{p s}^{2}+\sigma_{p \perp}^{2}} \\
\sigma_{p s}=-\left[b_{r} \delta \sigma_{r}+b_{z}\left(\sigma_{z s}+\delta \sigma_{z x}\right)\right] T, & \sigma_{p \perp}=-\left[b_{r} \sigma_{r}+b_{z} \sigma_{z x}\right] \sqrt{1-\delta^{2}} T \\
\sigma_{r}=r^{\prime}(x) \sigma_{x}, & \mu_{p}=\frac{1}{p(r, z)} \mathcal{A} p(r, z), \\
\sigma_{z s}(z, x)=\sigma_{v s}(x), & \sigma_{z x}(z, x)=\sigma_{v x}+\frac{h^{\prime}(x)}{h(x)} \sigma_{x} .
\end{aligned}
$$

and $\mathcal{A}$ is the infinitesimal generate associated with the bi-variate Markovian process $(r, z)$.

The partial differential equation for zero coupon bond prices can be determined by noting that $p_{T} m$ must be a Martingale, which implies (see equation 89)

$$
\Lambda_{p} \equiv \frac{\mu_{p}-r}{\sigma_{p}}=-\delta_{p} \Lambda-\sqrt{1-\delta_{p}^{2}} \Lambda_{\perp}
$$

which is the exact pricing equation for zero coupon bonds.

In Dai (2000a), I show that a zeroth order approximation to the term structure model is consistent with empirical evidences against the expectations hypothesis (Campbell and Shiller (1991)) in the sense of Dai and Singleton (2000).

\footnotetext{
${ }^{27}$ The primitive state variables are $x$ and $k$. However, in equilibrium, with mild regularity conditions, there is a one-to-one mapping between the pair $(x, k)$ and the pair $(r, z)$. Thus, we can think of $(r, z)$ as the state-variables.

${ }^{28}$ The negative sign in front of $\sigma_{p}$ is a convention.
} 


\section{Conclusion}

Capitalism is characterized essentially by its ownership structure. Income distribution, on the other hand, defines the look and feel, though not the nature, of capitalism. In the formative years of capitalism, which was the subject of inquiry by Adam Smith, David Ricardo, and Karl Marx, income distribution is tilted heavily in favor of the capitalists. While Karl Marx recognized this fact correctly, he made the fateful error in treating the prevailing form of income distribution as the defining characteristics of capitalism. Modern history, much of the look and feel of which has been influenced by his call for abandoning capitalism in favor of a new political economy that avoids the inevitable "economic crises", proves him wrong. With the emergence of labor unions, the adoption of anti-trust laws, and the institution of progressive tax codes and government income transfers, the income distribution in a modern capitalist economy is decisively different from that known to Marx. The post-war experiences of major capitalist economies suggest that the contemporaneous form of income distribution is compatible with stable economic growth without major economic crises. In the United States, this new form of income distribution took shape during or shortly after the world war II, spurred partly by war time government activism and partly by the influence of Keynesian. This basic economic fact was noted by several great economists of the era, such as Leontief and Klein. In Leontief (1946)'s mind, the prevailing mode of wage determination in mid 40's was a Stackelberg game between a strong union (a monopoly seller of labor) and a competitive firm. Klein (1950) formalized his notion of sticky wage in his wage demand function, as one of the three equations characterizing his exogenously specified statistical model of the consumption function.

This paper integrates these ideas into a dynamic model of intertemporal consumption, portfolio selection, and asset pricing, by proposing a realistic wage income process that enters the capitalist's problem as the cost of labor. The model is analytically solved, in both the discrete-time, deterministic case and the continuous-time case with production shock and labor income risk. I show that dynamics of business cycles are largely determined by the interaction between two components of the aggregate consumption: the capitalist's consumption and the worker's consumption, or equivalently, by the interaction between the aggregate output and labor cost. These predictions of the model are consistent with the Keynesian perspective, but are inconsistent with the predictions by real business cycle models. I also show that the model gives rise to a two-factor equity pricing model with

human capital, and a structural link between the macro economy and the term structure of interest rates.

The paper leaves open the important question of the optimality of labor contracts as a solution to a wage bargaining game. The question will be addressed in a companion paper. 


\section{Appendices}

\section{A The Main Proposition}

The following statement summarizes all key assumptions of the per capita, or detrended, economy.

Model 1 Consider a closed production economy with two infinitely lived agents: the capitalist and the worker. Let $c(t)$ be the aggregate consumption, $x(t)$ be the labor income demanded by the worker formalized in a wage contract, and $z(t) \equiv c(t)-x(t)$ be the capitalist's consumption.

a. Endowments: The capitalist has an initial endowment of physical capacity $k_{0}$, and nothing else. The worker is the owner of her human capital and is the monopoly seller of her labor.

b. Labor Contract: The worker demands and the capitalist accepts the following wage bill:

$$
d x(t)=\mu_{x}(x(t), z(t)) d t+\sigma_{x}(x(t), z(t)) d B_{x}
$$

where $x(0)=x_{0}$, and

$$
\mu_{x}(x, z)=l_{0}(x)+l_{1}(x) z+l_{2}(x) z^{2}, \sigma_{x}(x, z)=l_{3}(x) z,
$$

where $l_{2}(x)>0$ and $l_{3}(x)>0$.

c. Production: The capitalist has access to two production technologies.

1. The riskless technology pays a real interest rate of $r$.

2. The risky technology pays a "dividend" $d(t)$, and has an ex-dividend price of $s(t)$, with the total return process given by

$$
\frac{d s+d d t}{s}=\mu_{s} d t+\sigma_{s} d B_{s}
$$

The correlation between $B_{s}$ and $B_{x}$ is $\delta<0$.

3. Both the riskless rate $r$ and the Sharpe ratio $\Lambda=\frac{\mu_{s}-r}{\sigma_{s}}$ depend only the labor income $x$. They do not the level of physical capital, nor on time $t$ explicitly.

d. A Console Bond: A console bond exists and its net supply is zero. Let $\psi$ be the constant rate of coupon flow, and $p$ be the ex-coupon price of the console bond. Without loss of generality, its stochastic development can be written as

$$
\frac{d p+\psi d t}{p}=\mu_{p} d t-\sigma_{p}\left(\delta_{p} d B_{s}+\sqrt{1-\delta_{p}^{2}} d B_{\perp}\right) .
$$

where $\mu_{p}$ and $\sigma_{p}$ are to be determined. The Sharpe ratio of the console bond is defined by $\Lambda_{p}=\frac{\mu_{p}-r}{\sigma_{p}}$. 
e. Welfare Functions: The capitalist has a power utility function over his consumption $z(t)$. That is, he solves the following consumption choice and portfolio selection problem:

$$
\max _{z(t), \alpha(t): 0 \leq t \leq \infty} E\left[\int_{0}^{\infty} e^{-\rho t} \frac{z(t)^{\gamma}}{\gamma} d t \mid k(0)=k_{0}, x(0)=x_{0}\right],
$$

where $\gamma<0$ and $\rho>0$, subject to the budget constraint:

$$
d k(t)=\left[\left[\left(\mu_{s}-r\right) \alpha(t)+r\right] k(t)-z(t)-x(t)\right] d t+\alpha(t) \sigma_{s} k(t) d B_{s}, \text { and } k(t) \geq 0
$$

f. Scale-Independence: We assume that the indirect utility function, defined by,

$$
V(t ; k(t), x(t))=\max _{z(s), \alpha(s): s \geq t} E\left[\int_{t}^{\infty} e^{-\rho s} \frac{z(s)^{\gamma}}{\gamma} d s \mid k(t), x(t)\right],
$$

takes the following form:

$$
\begin{aligned}
V(t ; k, x) & =e^{-\rho t} J(k, x), \\
J(k, x) & =\phi \frac{(k-f(x))^{\gamma}}{\gamma}
\end{aligned}
$$

for some constant $\phi>0$, and some function $f(x)$, with the property $f(0)=0$ and $f^{\prime}(x)>0$ (thus $f(x)$ is non-negative for $x>0$ ).

Proposition 1 Assume that $k_{0}>f\left(x_{0}\right)$, and the transversality condition,

$$
\lim _{t \rightarrow \infty} E_{0}\left[e^{-\rho t} J(k(t), x(t))\right]=0,
$$

holds, then Model 1 has a unique equilibrium solution with the following properties:

1. The "habit level of capital stock", $f(x)$, is nonlinear, and is given by

$$
f(x)=\eta \int_{0}^{x} e^{-\int_{0}^{u} \frac{2 l_{2}(v)}{l_{3}(v)^{2}} d v} d u
$$

where $\eta>0$.

2. The riskless rate is state-dependent, and is given by

$$
r(x)=\frac{x+l_{0}(x) f^{\prime}(x)}{f(x)} .
$$

Furthermore, for $x>0, r^{\prime}(x)>0$. 
3. The Sharpe ratio is state-dependent, and is given by

$$
\Lambda(x)=(1-\gamma)\left[g(x)-\delta l_{3}(x) h(x) f^{\prime}(x)\right],
$$

where $g(x)$ and $h(x)$ jointly solve

$$
\begin{aligned}
\frac{h(x)^{\gamma-1}}{\phi} & =\left[1+l_{1}(x) f^{\prime}(x)\right]+(1-\gamma) l_{3}(x)^{2} h(x) f^{\prime}(x)^{2}-\delta l_{3}(x)(1-\gamma) g(x) f^{\prime}(x), \\
0 & =\frac{1-\gamma}{2} g(x)^{2}-\frac{1-\gamma}{\gamma} \delta l_{3}(x) h(x) f^{\prime}(x) g(x)+r(x)-\frac{\rho}{\gamma} \\
& +\frac{1-\gamma}{\gamma}\left[1+l_{1}(x) f^{\prime}(x)\right] h(x)+\frac{(1-\gamma)(2-\gamma)}{2 \gamma} l_{3}(x)^{2} h(x) f^{\prime}(x)^{2},
\end{aligned}
$$

provided that

$$
\begin{gathered}
\delta^{2} l_{3}(x)^{2} h(x)^{2} f^{\prime}(x)^{2} \geq \\
\frac{2 \gamma}{1-\gamma}\left[\gamma r(x)-\rho+(1-\gamma) \frac{h(x)^{\gamma}}{\phi}+\frac{(1-\gamma)(2-\gamma)}{2} l_{3}(x)^{2} h(x)^{2} f^{\prime}(x)^{2}\right] .
\end{gathered}
$$

4. The optimal consumption policy is given by

$$
z^{*}=h(x)(k-f(x)) .
$$

and the optimal portfolio policy is given by

$$
\alpha^{*}=\frac{g(x)}{\sigma_{s}} \frac{k-f(x)}{k} .
$$

5. The conditional volatility of the production return in the equilibrium is given by

$$
\sigma_{s}=\frac{k-f(x)}{k} g(x) .
$$

6. The equilibrium capital stock is given by

$$
\begin{aligned}
\frac{d(k-f(x))}{k-f(x)} & =\mu_{v} d t+\sigma_{v s} d B_{s}+\sigma_{v x} d B_{x} \\
\mu_{v} & =\frac{r(x)-\rho}{1-\gamma}+\frac{2-\gamma}{2(1-\gamma)^{2}} \Lambda(x)^{2}+\frac{2-\gamma}{2}\left(1-\delta^{2}\right) l_{3}(x)^{2} h(x)^{2} f^{\prime}(x)^{2}, \\
\sigma_{v s} & =g(x), \sigma_{v x}=-l_{3}(x) h(x) f^{\prime}(x) .
\end{aligned}
$$

Furthermore, $k_{0}>f\left(x_{0}\right)$ implies $k(t) \geq f(x(t))$ for $0 \leq t \leq \infty$.

7. Let $\mathcal{D}=\{x:(139)$ holds $\}$. Then for $x \in \mathcal{D}, h(x)>0, g(x)>0$ and $\Lambda(x)>0$.

8. The transversality condition is satisfied if

$$
\rho \geq \gamma r(x)+\frac{\gamma}{2(1-\gamma)} \Lambda(x)^{2}+\frac{\gamma(1-\gamma)}{2}\left(1-\delta^{2}\right) l_{3}(x)^{2} h(x)^{2} f^{\prime}(x)^{2} .
$$

Furthermore, for $x \in \mathcal{D}$, (144) is implied by (139).

To prove the proposition, I will first consider the special case when the bond market does not exist. This is the incomplete market case, and the proof is given in Appendix B. The proof for the general, or complete market, case is given in Appendix C. 


\section{B Proof of Proposition 1: Incomplete Market Case}

\section{B.1 First Order Conditions}

The portfolio selection problem is a standard one, with an important twist to be explained below. Since I am working in an incomplete market setting, I use the dynamic programming approach. Assuming, and later verifying through consistency check, that the indirect utility function takes the following form: $V(t ; k(t), x(t))=e^{-\rho t} J(k(t), x(t))$, I arrive at the Hamilton-Jacobi-Bellman equation:

$$
\begin{aligned}
0 & =\max _{z(t), \alpha(t)} \frac{z(t)^{\gamma}}{\gamma}-\rho J \\
& +\left(\left[\left(\mu_{s}-r\right) \alpha(t)+r\right] k(t)-z(t)-x(t)\right) J_{k}+\frac{1}{2} \alpha(t)^{2} \sigma_{s}^{2} k(t)^{2} J_{k k} \\
& +\left[l_{0}(x)+l_{1}(x) z+l_{2}(x) z^{2}\right] J_{x}+\frac{1}{2} l_{3}(x)^{2} z^{2} J_{x x} \\
& +\delta \alpha(t) \sigma_{s} k(t) l_{3}(x) z(t) J_{k x}
\end{aligned}
$$

The first order condition for optimal portfolio policy is given by

$$
\left(\mu_{s}-r\right) k J_{k}+\sigma_{s}^{2} k^{2} J_{k k} \alpha^{*}+\delta \sigma_{s} l_{3}(x) z^{*} k J_{k x}=0 .
$$

The first order condition for optimal consumption policy is given by

$$
z^{* \gamma-1}-J_{k}+\left[l_{1}(x)+l_{2}(x) z^{*}\right] J_{x}+l_{3}(x) z^{*} J_{x x}+\delta \sigma_{s} l_{3}(x) k J_{k x} \alpha^{*}=0 .
$$

From the proposed indirect utility function (134), I have

$$
\begin{aligned}
J_{k} & =\frac{\gamma}{k-f(x)} J, \\
J_{k k} & =\frac{\gamma(\gamma-1)}{(k-f(x))^{2}} J, \\
J_{x} & =-\frac{\gamma f^{\prime}(x)}{k-f(x)} J \\
J_{x x} & =-\frac{\gamma f^{\prime \prime}(x)}{k-f(x)} J+\frac{\gamma(\gamma-1) f^{\prime}(x)^{2}}{(k-f(x))^{2}} J \\
J_{k x} & =\frac{\gamma(1-\gamma) f^{\prime}(x)}{(k-f(x))^{2}} J
\end{aligned}
$$

Assuming that the optimal consumption and portfolio policies take the following form:

$$
\begin{aligned}
z^{*} & =h(x)(w-f(x)), \\
\alpha^{*} & =\frac{g(x)}{\sigma_{s}} \frac{k-f(x)}{w}
\end{aligned}
$$

equation (146) becomes:

$$
g(x)=\frac{\Lambda}{1-\gamma}+\delta l_{3}(x) h(x) f^{\prime}(x)
$$


Substituting equations (154) and (155) into equation (147), I have

$$
\begin{gathered}
0=-\phi h(x) f^{\prime}(x)(k-f(x))\left[l_{2}(x) f^{\prime}(x)+\frac{1}{2} l_{3}(x)^{2} f^{\prime \prime}(x)\right] \\
+\phi\left[\frac{h(x)^{\gamma-1}}{\phi}-1-l_{1}(x) f^{\prime}(x)-l_{3}(x)^{2}(1-\gamma) h(x) f^{\prime}(x)^{2}+\delta l_{3}(x)(1-\gamma) g(x) f^{\prime}(x)\right] .
\end{gathered}
$$

This equation is inhomogeneous in $k-f(x)$, and will hold for arbitrary $k$ and $x$ if and only if

$$
l_{2}(x) f^{\prime}(x)+\frac{1}{2} l_{3}(x)^{2} f^{\prime \prime}(x)=0
$$

and

$$
\frac{h(x)^{\gamma-1}}{\phi}=\left(1+l_{1}(x) f^{\prime}(x)\right)+(1-\gamma) l_{3}(x)^{2} h(x) f^{\prime}(x)^{2}-(1-\gamma) \delta l_{3}(x) g(x) f^{\prime}(x) .
$$

Since $f(0)=0,{ }^{29}$ equation $(157)$ can be easily solved:

$$
f(x)=\eta \int_{0}^{x} e^{-\int_{0}^{u} \frac{2 l_{2}(v)}{l_{3}(v)^{2}} d v} d u .
$$

Thus, the first order conditions for optimality determine, uniquely, the functional form of $f(x)$ !

\section{B.2 Investment Opportunity Set}

I will now show that both $r(x)$ and $\Lambda(x)$ are uniquely determined, by virtue of the fact that $f(x)$ takes a specific form. To show this, we examine the implication of equation (145) evaluated at the optimal policies:

$$
\begin{aligned}
0 & =\frac{h(x)^{\gamma}}{\gamma \phi}-\frac{\rho}{\gamma}+\frac{1}{2}(\gamma-1) g(x)^{2}-(\gamma-1) \delta l_{3}(x) g(x) h(x) f^{\prime}(x) \\
& +\frac{\gamma-1}{2} l_{3}(x)^{2} h(x)^{2} f^{\prime}(x)^{2}+\Lambda(x) g(x)+r(x)-h(x)\left(1+l_{1}(x) f^{\prime}(x)\right) \\
& +\frac{r(x) f(x)-x-l_{0}(x) f^{\prime}(x)}{k-f(x)}-h(x)^{2}\left[l_{2}(x) f^{\prime}(x)+\frac{l_{3}(x)^{2}}{2} f^{\prime \prime}(x)\right] \\
& =\frac{1}{2}(1-\gamma) g(x)^{2}-\frac{1-\gamma}{\gamma} \delta l_{3}(x) h(x) f^{\prime}(x) g(x) \\
& +\left[r(x)-\frac{\rho}{\gamma}+\frac{1-\gamma}{\gamma} h(x)\left(1+l_{1}(x) f^{\prime}(x)\right)+\frac{(1-\gamma)(2-\gamma)}{2 \gamma} l_{3}(x)^{2} h(x)^{2} f^{\prime}(x)^{2}\right] \\
& +\frac{r(x) f(x)-x-l_{0}(x) f^{\prime}(x)}{k-f(x)} .
\end{aligned}
$$

\footnotetext{
${ }^{29} \mathrm{I}$ will justify this assumption soon.
} 
The last equality follows from equations (155), (158), and (157).

Note the right hand side of equation (160) is inhomogeneous. It holds for any $k$ and $x$, if and only if

$$
r(x) f(x)-x-l_{0}(x) f^{\prime}(x),
$$

and

$$
\begin{gathered}
0=\frac{1}{2}(1-\gamma) g(x)^{2}-\frac{1-\gamma}{\gamma} \delta l_{3}(x) h(x) f^{\prime}(x) g(x) \\
+\left[r(x)-\frac{\rho}{\gamma}+\frac{1-\gamma}{\gamma} h(x)\left(1+l_{1}(x) f^{\prime}(x)\right)+\frac{(1-\gamma)(2-\gamma)}{2 \gamma} l_{3}(x)^{2} h(x)^{2} f^{\prime}(x)^{2}\right] .
\end{gathered}
$$

Given $f(x)$, equation (136) determines the riskless rate, and equations (162) and (158) jointly determine the functions $g(x)$ and $h(x)$, which determine $\Lambda(x)$. Since $f(x)$ is unique, both $r(x)$ and $\Lambda(x)$ are unique.

In order for $r(x)$ to be well-defined, equation (136) implies that $f(0)$ must be zero, justifying the assumption made earlier in solving equation (157).

Equation (162) is quadratic in $g(x)$. Thus, $g(x)$ exists if and only if equation (139) holds.

\section{B.3 Market Clearing Conditions}

The conditional volatility of the total return to risky production is determined by imposing the market clearing condition:

$$
\alpha^{*}=1
$$

which implies

$$
\sigma_{s}=\frac{k-f(x)}{f(x)} g(x) .
$$

Thus, the investment opportunity set is unique, and determined endogenously in the equilibrium. The riskless rate, the Sharpe ratio, and the conditional volatility to production return are stochastic, because they are explicit functions of two stochastic state variables, $k$ and $x$.

The equilibrium capital stock, equation (143), is obtained by noting that under the market clearing conditions:

$$
z^{*}+x=d, \alpha^{*}=1,
$$

the capital stock is equal to the ex-dividend price of the production technology. Thus, its stochastic development in the equilibrium is given by

$$
\begin{aligned}
d k & =\left(\mu_{s} k-z^{*}-x\right) d t+\sigma_{s} k d B_{s} \\
& =[(\Lambda(x) g(x)+r(x)-h(x))(k-f(x))+r f(x)-x] d t+g(x)(k-f(x)) d B_{s} .
\end{aligned}
$$


On the other hand,

$$
\begin{aligned}
d f(x) & =\left[f^{\prime}(x)\left(l_{0}(x)+l_{1}(x) z^{*}+l_{2}(x) z^{* 2}\right)+\frac{l_{3}(x)^{2}}{2} f^{\prime \prime}(x) z^{* 2}\right] d t+f^{\prime}(x) l_{3}(x) z^{*} d B_{x} \\
& =\left[l_{0}(x)+l_{1}(x) h(x)(k-f(x))\right] f^{\prime}(x) d t+l_{3}(x) h(x) f^{\prime}(x)(k-f(x)) d B_{x} .
\end{aligned}
$$

Thus,

$$
\begin{aligned}
d(k-f(x)) & =\left[\Lambda(x) g(x)+r(x)-h(x)\left(1+l_{1}(x) f^{\prime}(x)\right)\right](k-f(x) d t \\
& +g(x)(k-f(x)) d B_{s}-l_{3}(x) h(x) f^{\prime}(x)(k-f(x)) d B_{x} .
\end{aligned}
$$

Equation (143) follows immediately. Thus, in equilibrium, $k-f(x)$ grows at an exponential rate, and will be non-negative as long as it is initially so.

\section{B.4 Transversality Condition}

Applying Ito's lemma to $\log V(t)=-\rho t+\log J(k(t), x(t))$, I have

$$
d \log V(t)=\left[-\rho+\gamma\left[\mu_{v}-\frac{1}{2}\left(\sigma_{v s}^{2}+\sigma_{v x}^{2}+2 \delta \sigma_{v s} \sigma_{v x}\right)\right]\right] d t+\gamma \sigma_{v s} d B_{s}+\gamma \sigma_{v x} d B_{x} .
$$

It follows that, using equation (143),

$$
\begin{aligned}
\frac{d V(t)}{V(t)} & =\left[-\rho+\gamma \mu_{v}-\frac{\gamma(1-\gamma)}{2}\left(\sigma_{v s}^{2}+\sigma_{v x}^{2}+2 \delta \sigma_{v s} \sigma_{v x}\right)\right] d t+\gamma \sigma_{v s} d B_{s}+\gamma \sigma_{v x} d B_{x} \\
& =\frac{1}{1-\gamma}\left[\gamma r(x)+\frac{\gamma}{2(1-\gamma)} \Lambda(x)^{2}+\frac{\gamma(1-\gamma)}{2}\left(1-\delta^{2}\right) l_{3}(x)^{2} h(x)^{2} f^{\prime}(x)^{2}-\rho\right] d t \\
& +\gamma g(x) d B_{s}-\gamma l_{3}(x) h(x) f^{\prime}(x) d B_{x} .
\end{aligned}
$$

Thus, $V(t)$ is a supermartingale when equation (144) holds. Transversality condition follows immediately.

To show that (139) implies (144), I first establish $h(x)>0$ and $g(x)>0$. For a fixed $x \in \mathcal{D}$, think of both sides of equation (158) as functions of $h(x)$. The left hand side is monotonically decreasing in $h(x)$, from $+\infty$ to 0 , and the right hand side of equation (158) is monotonically increasing in $h(x)$. Thus, the two functions always intersect at a positive $h(x)$. This proves $h(x)>0$. Next, under the restriction (139), the solution to equation (162) must satisfy ${ }^{30}$

$$
g(x) \geq \frac{\delta l_{3}(x) h(x) f^{\prime}(x)}{\gamma}>0
$$

which implies that $\Lambda(x) \geq \frac{(1-\gamma)^{2}}{\gamma} \delta l_{3}(x) h(x) f^{\prime}(x)>0$.

Now, the right hand side of equation (144) can be evaluated using equation (162), and is given by

$-(1-\gamma)\left(1+l_{1}(x) f^{\prime}(x)\right) h(x)-(1-\gamma)^{2} l_{3}(x)^{2} h(x)^{2} f^{\prime}(x)^{2}+(1-\gamma)^{2} \delta l_{3}(x) h(x) f^{\prime}(x) g(x)<0$.

With the left hand side equal to $\rho>0$, the transversality condition is automatically satisfied.

\footnotetext{
${ }^{30}$ There are two roots to equation $(162)$. The negative root is ruled out for economic reasons.
} 


\section{B.5 Optimality}

Finally, let us verify that the solution to the first order conditions is optimal. In equilibrium, the hessian matrix is

$$
\begin{aligned}
& \left(\begin{array}{cc}
\sigma_{s}^{2} k^{2} J_{k k} & \delta l_{3}(x) \sigma_{s} k J_{k x} \\
\delta l_{3}(x) \sigma_{s} k J_{k x} & (\gamma-1) z^{* \gamma-2}+\left(2 l_{2}(x) J_{x}+l_{3}(x)^{2} J_{x x}\right)
\end{array}\right)=(\gamma-1) \phi \times \\
& g(x)^{2}(k-f(x))^{\gamma} \\
& \left(\begin{array}{cc}
\delta l_{3}(x) g(x) f^{\prime}(x)(k-f(x))^{\gamma-1} \\
\delta l_{3}(x) g(x) f^{\prime}(x)(k-f(x))^{\gamma-1} & {\left[\frac{h(x)^{\gamma-2}}{\phi}+l_{3}(x)^{2} f^{\prime}(x)^{2}\right](k-f(x))^{\gamma-2}}
\end{array}\right) .
\end{aligned}
$$

It is easy to check that this matrix is negative-definite.

\section{Proof of Proposition 1: Complete Market Case and the Derivation of the Pricing Kernel}

Let $\alpha$ and $\alpha_{p}$ be the share of wealth (after consumption) invested in the risky production and the console bond, respectively. The budget constraint becomes

$$
\begin{aligned}
d k & =\left\{\left[\left(\mu_{s}-r\right) \alpha+\left(\mu_{p}-r\right) \alpha_{p}+r\right] k-z-x\right\} d t+\alpha \sigma_{s} k d B_{s} \\
& -\alpha_{p} \sigma_{p} k\left(\delta_{p} d B_{s}+\sqrt{1-\delta_{p}^{2}} d B_{\perp}\right) .
\end{aligned}
$$

Thus, the Hamilton-Jacobian-Bellman equation becomes

$$
\begin{aligned}
0 & =\max _{z, \alpha, \alpha_{p}} \frac{z^{\gamma}}{\gamma}-\rho J+\left\{\left[\left(\mu_{s}-r\right) \alpha+\left(\mu_{p}-r\right) \alpha_{p}+r\right] k-z-x\right\} J_{k} \\
& +\frac{1}{2}\left[\left(\alpha \sigma_{s}-\alpha_{p} \delta_{p} \sigma_{p}\right)^{2}+\alpha_{p}^{2}\left(1-\delta_{p}^{2}\right) \sigma_{p}^{2}\right] k^{2} J_{k k}+\mu_{x} J_{x}+\frac{1}{2} \sigma_{x}^{2} J_{x x} \\
& +\left[\left(\alpha \sigma_{s}-\alpha_{p} \delta_{p} \sigma_{p}\right) \delta \sigma_{x}-\alpha_{p} \sqrt{1-\delta_{p}^{2}} \sigma_{p} \sqrt{1-\delta^{2}} \sigma_{x}\right] k J_{k x}
\end{aligned}
$$

The first order conditions for $\alpha$ and $\alpha_{p}$ are:

$$
\begin{aligned}
0= & \left(\mu_{s}-r\right) k J_{k}+\left(\alpha \sigma_{s}-\alpha_{p} \delta_{p} \sigma_{p}\right) \sigma_{s} k^{2} J_{k k}+\delta \sigma_{s} \sigma_{x} k J_{k x} \\
0= & \left(\mu_{p}-r\right) k J_{k}-\left(\alpha \sigma_{s}-\alpha_{p} \delta_{p} \sigma_{p}\right) \delta_{p} \sigma_{p} k^{2} J_{k k} \\
& +\left(\delta_{p} \delta-\sqrt{1-\delta_{p}^{2}} \sqrt{1-\delta^{2}}\right) \sigma_{p} \sigma_{x} k J_{k x}
\end{aligned}
$$

Solving, I obtain

$$
\begin{aligned}
\alpha^{*} & =\frac{g-\delta_{p} g_{p}}{\sigma_{s}\left(1-\delta_{p}^{2}\right)}, \\
\alpha_{p}^{*} & =-\frac{g_{p}-\delta_{p} g}{\sigma_{p}\left(1-\delta_{p}^{2}\right)}, \text { where, } \\
g & =\frac{\Lambda}{1-\gamma}+\delta l_{3}(x) h(x) f^{\prime}(x), \\
g_{p} & =-\frac{\Lambda_{p}}{1-\gamma}+\left(\delta_{p} \delta+\sqrt{1-\delta_{p}^{2}} \sqrt{1-\delta^{2}}\right) l_{3}(x) h(x) f^{\prime}(x),
\end{aligned}
$$


where $\Lambda_{p}=\frac{\mu_{p}-r}{\sigma_{p}}$ is the Sharpe ratio of the console bond.

Imposing the market clearing condition $\alpha_{p}^{*}=0$, I obtain

$$
g_{p}=\delta_{p} g
$$

or equivalently

$$
\Lambda_{p}=-\delta_{p} \Lambda+(1-\gamma) \sqrt{1-\delta_{p}^{2}} \sqrt{1-\delta^{2}} l_{3}(x) h(x) f^{\prime}(x)
$$

In general, the stochastic development of the pricing kernel, or the state price $m(t)$, of the model can be written as

$$
\frac{d m(t)}{m(t)}=-r d t-\Lambda d B_{s}-\Lambda_{\perp} d B_{\perp}
$$

where the drift of $(-r)$ comes from the fact that a bank account deflated by the state price must be a Martingale. ${ }^{31}$ Furthermore, the diffusion associated with the production shock is $(-\Lambda)$ because the equilibrium wealth process must be the price of the consumption stream, therefore the deflated gain process, $k(t) m(t)+\int_{0}^{t} c(s) m(s) d s$, must be a Martingale.

Since $p$ is the price of the coupon stream $\psi, p(t) m(t)+\int_{0}^{t} \psi m(s) d s$ must also be a Martingale. This implies that the Sharpe ratio of the console bond must be

$$
\Lambda_{p}=-\delta_{p} \Lambda-\sqrt{1-\delta_{p}^{2}} \Lambda_{\perp}
$$

Equation (186) may be viewed as a version of the consumption based capital asset pricing model (CCAPM) applied to the bond market.

Comparing equations (184) and (186), I conclude that

$$
\Lambda_{\perp}=-(1-\gamma) \sqrt{1-\delta^{2}} l_{3}(x) h(x) f^{\prime}(x) .
$$

This is the equilibrium price of risk associated with the random shock $B_{\perp}$.

Once I impose the market clearing condition for the console bond, the rest of the model is exactly the same as the incomplete market case. That is, the functions $r(x), \Lambda(x), f(x), h(x)$, and $g(x)$, will all be the same as before. The only effect of introducing a zero supply console bond into the agent's investment opportunity set is the endogenous and unique restriction on the equilibrium market price for the labor income risk.

\section{References}

Breeden, D. (1979). An intertemporal asset pricing model with stochastic consumption and investment opportunities. Journal of Financial Economics, 7:265-296.

Brown, T. M. (1952). Habit persistence and lags in consumer behavior. Econometrica, $20(3): 355-371$.

\footnotetext{
${ }^{31}$ See Duffie (1996).
} 
Campbell, J. Y. (1999). Asset prices, consumption, and the business cycle, in Handbook of Macroeconomics, ed., John Taylor and Michael Woodford, volume 1. North-Holland, Amsterdam.

Campbell, J. Y. (2000). Asset pricing at the millennium. Journal of Finance, forthcoming.

Campbell, J. Y. and Mankiw, N. G. (1987a). Are output fluctuations transitory? Quarterly Journal of Economics, 102(4):857-880.

Campbell, J. Y. and Mankiw, N. G. (1987b). Permanent and transitory components in macroeconomic fluctuations. Americal Economic Review, Papers and Proceedings of the Ninety-Nith Annual Meeting of the Americal Economic Association, 77(2):111-117.

Campbell, J. Y. and Shiller, R. J. (1991). Yield spreads and interest rate movements: A bird's eye view. Review of Economic Studies, 58:495-514.

Constantinides, G. (1990). Habit formation: A resolution of the equity premium puzzle. Journal of Political Economy, 98(3):519-543.

Cox, J. C., Ingersoll, J. E., and Ross, S. A. (1985). A theory of the term structure of interest rates. Econometrica, 53:385-408.

Dai, Q. (2000a). From equity premium puzzle to expectations puzzle: A general equilibrium production economy with stochastic habit formation.

Dai, Q. (2000b). Time-consistent labor contract and consumption policy: An extensive form game of labor income determination. Working paper, New York University.

Dai, Q. and Singleton, K. J. (2000). Expectations puzzles, time-varying risk premium, and dynamics of the term structure. Working paper.

Duffie, D. (1996). Dynamic Asset Pricing Theory, 2nd edition. Princeton University Press, Princeton, N.J.

Friedman, M. (1957). A Theory of the Consumption Function. Princeton: Princeton University Press.

Gibbons, R. (1992). Game Theory for Applied Economists. Princeton University Press.

Hodrick, R. J. and Prescott, E. C. (1997). Postwar u.s. business cycles: An empirical investigation. Journal of Money, Credit, and banking, 29(1):1-16.

Klein, L. R. (1950). Economic Fluctuations in the United States, 1921-1941, Cowles Commission for Research in Economics, Monograph No. 11. John Weily and Sons.

Kydland, F. E. and Prescott, E. C. (1982). Time to build and aggregate fluctuations. Econometrica, 50(6):1345-1370.

Leontief, W. (1946). The pure theory of guaranteed annual wage contract. Journal of Political Economy, 54:76-79. 
Lintner, J. (1965). Valuation of risk assets and the selection of risky investments in stock portfolios and capital budgets. Review of Economics and Statistics, pages 13-37.

Long, J. and Plosser, C. I. (1983). Real business cycles. Journal of Political Economy, 91(1):39-69.

Lucas, R. (1978). Asset prices in an exchange economy. Econometrica, 46:1429-1445.

Mankiw, N. G. (1989). Real business cycles: A new keynesian perspective. Journal of Economic Perspectives, 3(3):79-90.

Mehra, R. and Prescott, E. C. (1985). The equity premium: A puzzle. Journal of Monetary Economics, 15:145-161.

Merton, R. C. (1973). An intertemporal capital asset pricing model. Econometrica, 41:867888.

Merton, R. C. (1992). Continuous-time Finance. Blackwell, Cambridge MA \& Oxford UK.

Romer, P. M. (1994). The origins of endogenous growth. Journal of Economic Perspectives, $8(1): 3-22$.

Sharpe, W. F. (1964). Capital asset prices: A theory of market equilibrium under conditions of risk. Journal of Finance, pages 429 - 442.

Solow, R. M. (1956). A contribution to the theory of economic growth. Quarterly Journal of Economics, 70:5-94.

Solow, R. M. (1957). Technical change and the aggregate production function. Review of Economics and Statistics, 39:312-320.

Stackelberg, H. v. (1934). Marktform und Gleichgewicht. Vienna: Julius Springer.

Stokey, N. L., Lucas, R., and Prescott, E. C. (1989). Recursive Methods in Economic Dynamics. Harvard University Press, Cambridge, Massachusetts, and London.

Summers, L. H. (1986). Some skeptical observations on real business cycle theory. Federal Reserve Bank of Minneapolis Quarterly Review, pages 23-27.

Sundaresan, S. M. (1989). Intertemporally dependent preferences and the volatility of consumption and wealth. Review of Financial Studies, 2:73-88.

Sundaresan, S. M. (2000). Continuous-time methods in finance: A review and an assessment. Journal of Finance, forthcoming.

Weil, P. (1989). The equity premium puzzle and the riskfree rate puzzle. Journal of Monetary Economics, 24:401-421.

Weil, P. (1993). Precautionary savings and the permanent income hypothesis. Review of Economic Studies, 60(2):367-383. 